\title{
CONCENTRATE SPRAYING IN DECIDUOUS ORCHARDS
}

\author{
by
}

JAMES MARSHALL

CANADA DEPARTMENT OF AGRICULTURE 



\title{
CONCENTRATE SPRAYING \\ IN DECIDUOUS ORCHARDS
}

\author{
by \\ JAMES MARSHALL \\ Entomology Laboratory \\ Summerland, British Columbia
}

SCIENCE SERVICE, ENTOMOLOGY DIVISION CANADA DEPARTMENT OF AGRICULTURE OTTAWA, ONTARIO

Price: $\$ 1.00$ 


\section{CONTENTS}

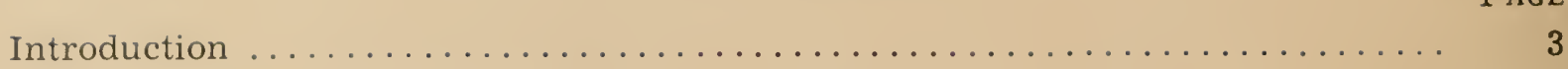

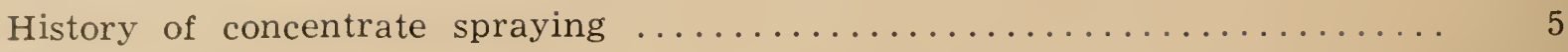

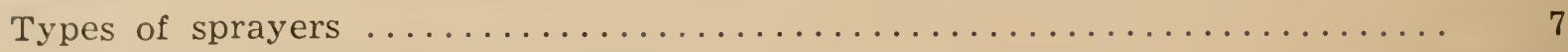

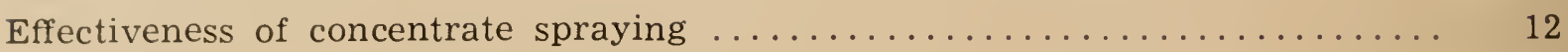

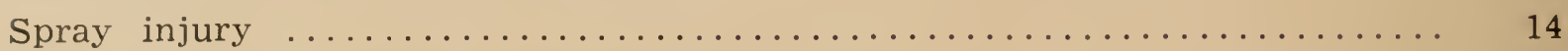

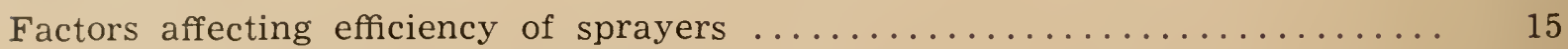

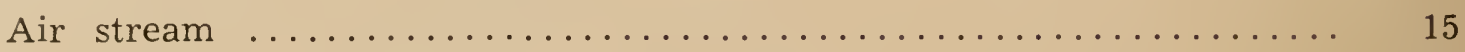

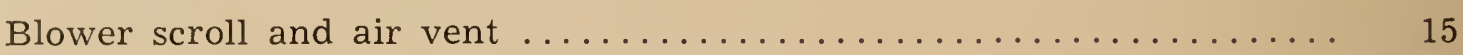

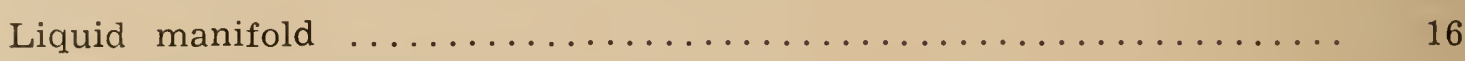

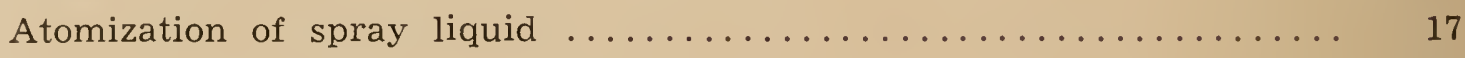

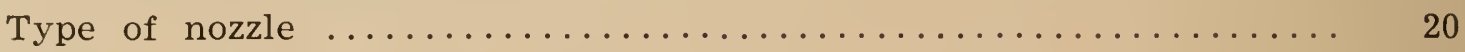

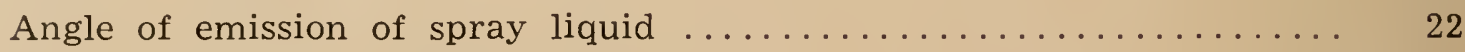

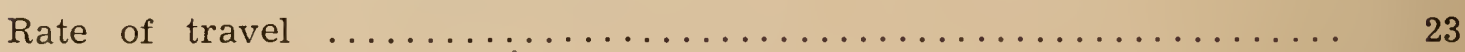

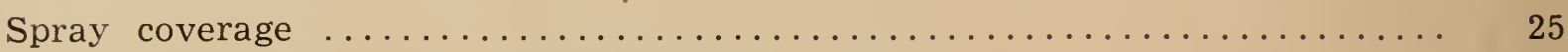

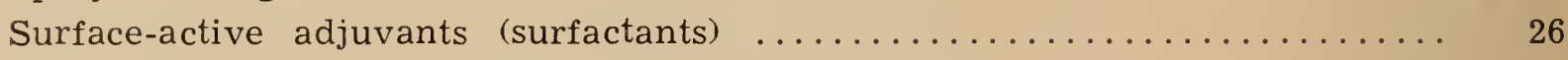

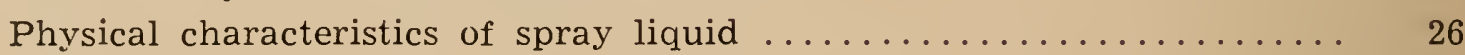

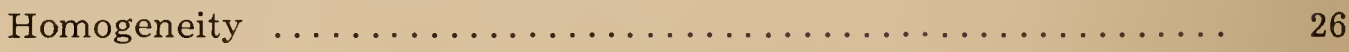

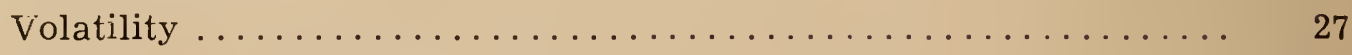

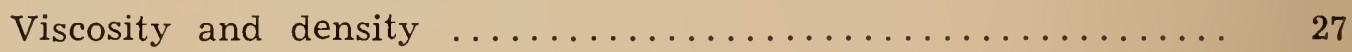

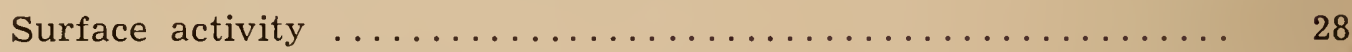

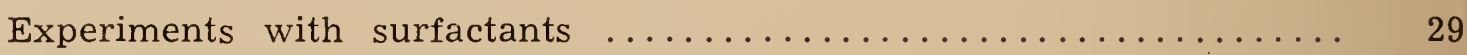

Type and quantity of surfactant necessary $\ldots \ldots \ldots \ldots \ldots \ldots \ldots \ldots . \ldots \ldots \ldots$

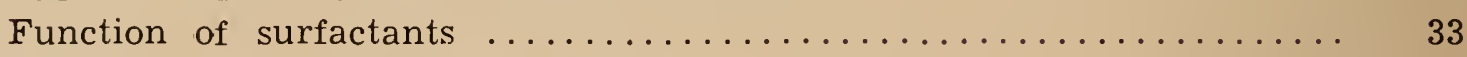

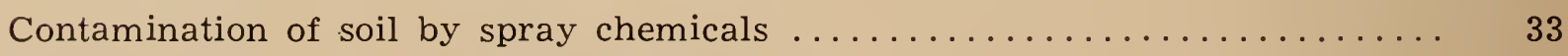

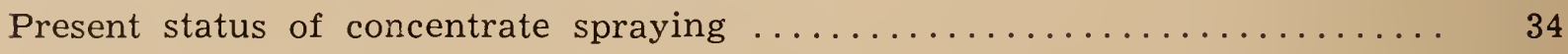

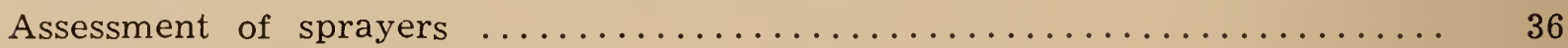

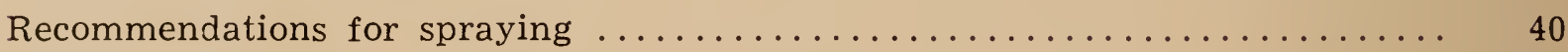

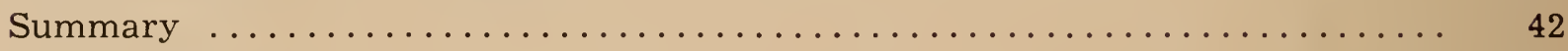

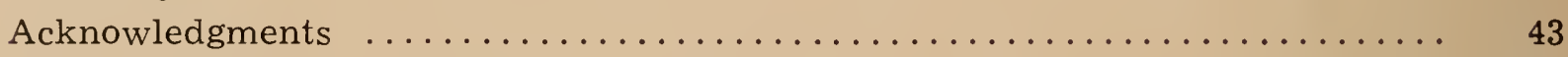

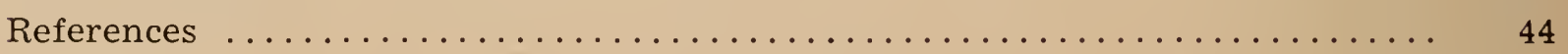




\section{INTRODUCTION}

Concentrate, or low-volume, spraying is a more complex procedure than the high-volume method that it has replaced in British Columbia, and which it is in process of replacing in a number of other fruit growing areas of the world. The new practice has been in commercial use in orchards for less than ten years, but has been the subject of a considerable number of technical and popular articles. Since none of these articles has dealt with the subject as a whole, it is timely to bring together and discuss the varied aspects of concentrate spraying in a single publication.

This bulletin is written for enquiring fruit growers as well as for technical workers. It deals as directly as possible, therefore, with the more distinctive features of concentrate spraying. Special consideration is given the use of surfactants because they are likely to be used widely in concentrate spraying though they are now used only in British Columbia. The literature on concentrate spraying is reviewed and pertinent information is added from experiments, or from experience, in British Columbia. Except for spray recommendations, tabular material is omitted.

In the approach to the problem it was necessary to deal empirically with many of the important features of the work. Large differences were sought; small differences were disregarded. As the British Columbia fruit industry was the first to mechanize its spraying operations with concentrate equipment, the development of the procedure should be of interest, and possibly of help, elsewhere.

In the 67-year history of the British Columbia tree fruit industry it is doubtful whether any production method has contributed so much to the welfare of the fruit grower as concentrate spraying. The new method of applying pesticides reduced the cost of controlling insects and diseases to about half that of the high-volume, hand-gun spraying of earlier days, and transformed a foul and irksome job into a relatively simple, routine operation. Five years after concentrate spraying was officially approved, it had been adopted by most of British Columbia's 3,500 fruit growers.

The course of spraying methods in other fruit growing areas of North America indicates that the orchardists of British Columbia have mechanized their spraying operations with unusual speed and unanimity. There was little debate about the relative merits of high-volume and low-volume spraying. Reasons for the growers ready acceptance of concentrate spraying were: (a) British Columbia's orchards are far removed from the principal fruit markets. Since high, fixed freight charges must be added to the cost of production, every care has to be taken to keep the cost of production to a minimum. (b) As the orchards average less than 10 acres in area, most of them cannot support heavy capital investment, e.g., large and expensive air-blast sprayers. (c) Few of the orchard tractors are capable of hauling heavy spray equipment at slow speed in the predominantly hilly orchards. (d) The horticulturists of the area are averse to hauling very heavy equipment through the orchards because of suspected ill effects of soil compaction. (e) Although many of the fruit trees of the area are about 20 feet high and 30 feet in diameter, they are pruned to allow adequate air circulation and entry of light; hence they are adapted to concentrate spraying with modestly powered machines. (f) Local 
manufacturers, who had no previous experience with spray applicators and hence nothing to unlearn, sensed the significance of the new method of spraying and quickly built the type of equipment that had been officially approved, and that the growers were beginning to demand. (g) Official advisers were nearly unanimous on the merits of concentrate spraying.

Nowadays the literature on orchard spraying is characterized by such terms as bulk spraying, high-volume spraying, low-volume spraying, highpressure spraying, air-blast spraying, mist spraying, concentrate spraying, and so forth. In England, where there is special interest in ultra low-volume spraying ( 3 to 10 gallons per acre), it has been proposed that what is generally referred to as concentrate spraying in North America should be more precisely described. Specific names should be given to spraying at dosages of up to 20 gallons per acre, 20 to 50 gallons per acre, and over 50 gallons per acre.

A simpler way of dealing with the confused terminology is to group orchard air-blast sprayers into two categories; high-volume sprayers and low-volume, or concentrate, sprayers. On this basis, a high-volume sprayer is one that induces dripping of spray liquid from the trees; a low-volume, or concentrate, sprayer is one that does not induce dripping. This distinction is advanced because perhaps the most important factor in orchard spraying is whether drip, or run-off occurs. The character of a spray deposit alters radically after the spray droplets coalesce and begin to move downwards. From a discrete, or spotted, deposit a blotched, or filmed, deposit takes form. Particularly in the control of fungus diseases, as discussed later, the character of the deposit is important. Equally important, spray injury to foliage or fruit is commonly intensified when the drip-point is almost reached or passed. If the trees are dry, the drip-point occurs in a mature British Columbia apple orchard when more than about 75 imperial gallons of spray liquid per acre are applied by an efficient concentrate sprayer. Inefficient machines, however, by heavily overspraying the lower limbs, can induce dripping with a considerably lower per-acre output. By the definition, such machines, though they may apply 60 gallons, or even less per acre, are not concentrate sprayers. 


\section{HISTORY OF CONCENTRATE SPRAYING}

What seems to have been the first serious attempt to get rid of the highpressure spray gun was made in 1925 by the Niagara Sprayer and Chemical Co., Middleport, New York. In that year the company introduced the Rex Liqui-Duster-(Private communication, Niagara Sprayer and Chemical Division, F.M.C., Middleport, New York, U.S.A.). The Liqui-Duster was equipped with a centrifugal blower and a low-pressure, centrifugal pump, both powered by a 12-horsepower gasoline engine. The machine developed an air stream with a velocity of 150 miles per hour at the nozzle of a four-inch, manually operated, metallic hose. The spray liquid was pumped into the air stream at a pressure of 40 pounds per square inch. The Liqui-Duster never became popular despite its appeal to the mechanically minded. In those days labor was cheap, and perhaps the ear-splitting wail of the blower was disconcerting.

In 1933 Parker (49) described a machine that atomized an oil solution of an insecticide and distributed it at 2.5 U.S. gallons per acre by means of an air stream from a fixed vent. The machine was successfully used in vineyards and prune orchards to control "leaf-hoppers, the brown apricot scale, red spider, and thrips." Oddly enough, although this pioneer work on concentrate spraying was done in California, the fruit growers of that state appear to be more hesitant about adopting the method than those in most other fruit growing areas.

Seven years later, Potts (51), who may aptly be termed the father of concentrate spraying, reported on the use of concentrated spray mixtures on forest, shade, and orchard trees. Using eight gallons of spray liquid per acre, he claimed satisfactory control of pests, and less foliage injury than from high-volume spraying. In 1942 French (19) mentioned that ground sprayers of the compressed-air type, ground sprayers of the blower type, and aircraft had been successfully used to apply concentrate spray liquids to various crops.

Potts and Friend (53) worked with a fixed-vent machine having an air output of 8,730 cubic feet per minute at a velocity of 124 miles per hour. The machine was fitted with a gear pump developing a pressure of 80 pounds per square inch. Reporting in 1946, these authors appear to have been the first to apply a clockwork mechanism to the study of droplet sizes and spray deposits in concentrate spraying. Their device exposed coated glass slides to the spray mist for predetermined periods of time.

Much of the pioneer work in concentrate spraying was done at Cornell University. Pratt (55) described a machine known as the Cornell experimental spray-duster that was the outcome of experiments begun in 1940. This machine was eventually produced commercially, and operated with success by many eastern and middle-western fruit growers. It featured a large, fixed "fishtail" so constructed as to direct the air-stream upwards through the trees at an angle of about 45 degrees. The Cornell type of concentrate sprayer is considerably larger and more powerful than those manufactured in British Columbia.

Brann $(7,10)$, has been responsible for a good share of the research on concentrate spraying. Having designed a spray nozzle for the purpose, he experimented with ultra low-volume applications. Using dormant oil at concentrations varying from 100 per cent downwards, he concluded that 25 per cent oil represented an optimum concentration. In controlling the European red 
mite, Metatetranychus ulmi (Koch), Brann et al. (8) determined that oil applied as a mist at 25 per cent concentration was two to three times as effective as an equal quantity of oil applied in a high-volume spray.

From Michigan, Mitchell $(40,42)$ reported on concentrate spraying investigations begun in 1947, and on the commercial application of the procedure. The fruit growers in that state have had generally satisfactory results from concentrate spraying, perhaps because they have not lacked authoritative information on the importance of adequate pruning, and on the relation of per-acre output, and rate of travel, to size and type of machine. The trend in Michigan is to an increased concentration of toxicants.

Burrell (13) noted that, in eastern New York State, concentrate spraying was the prevailing method; but in the western part of the state most of the fruit acreage was sprayed with large, high-volume machines. He warned against the purchase of conversion units ("hang-on" blowers) mounted on old, high-pressure sprayers, pointing out that such devices were generally inadequate.

A word of criticism of official caution about concentrate spraying was expressed in 1951 by Ring (57), a grower operating 200 acres of apple orchard in eastern United States: "In my travels round the country... there are many growers much confused about mist concentrates. They are afraid to try them. I believe this was good in the past but now growers need the advantages of concentrates more than ever to help to keep down the cost of production".

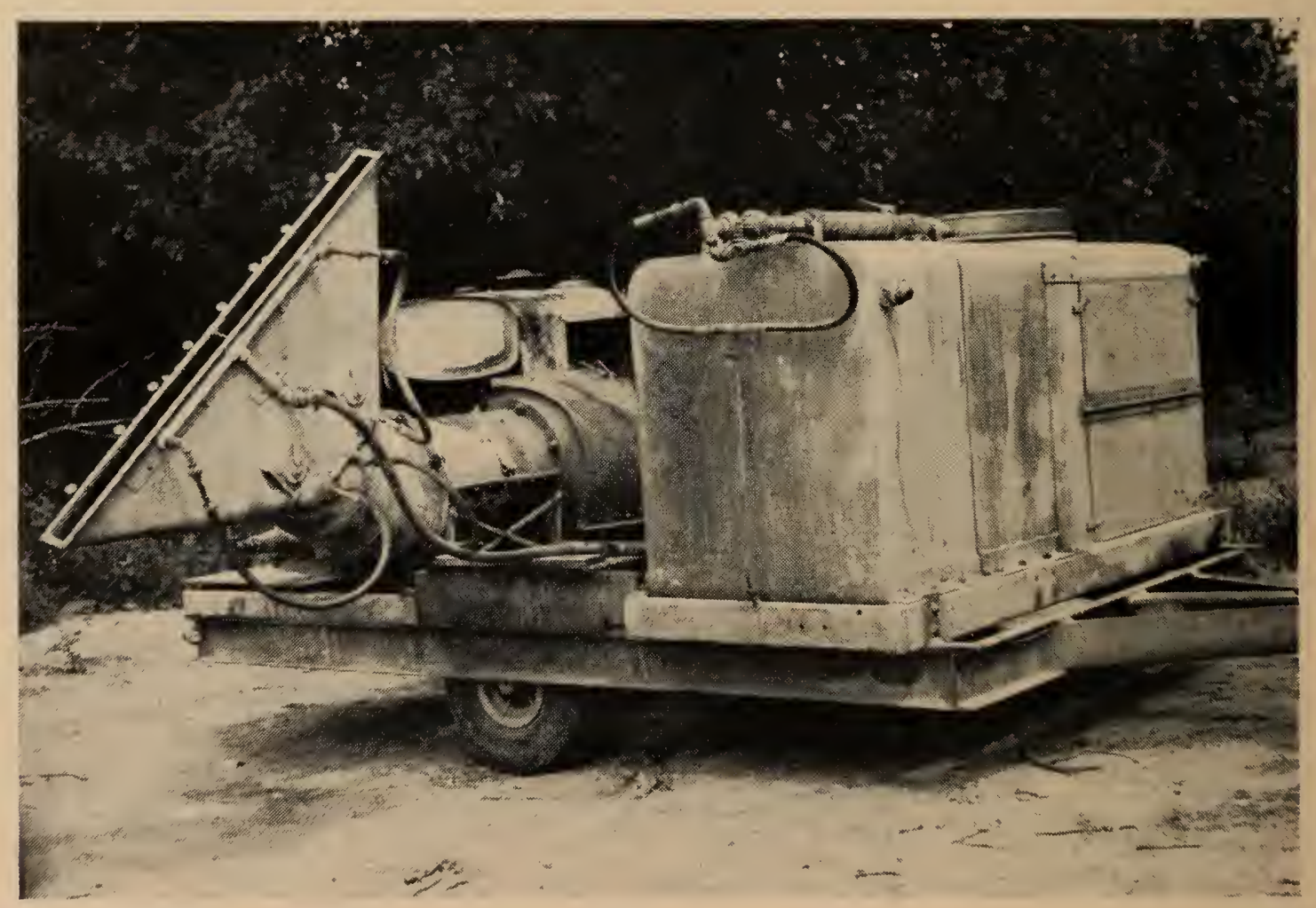

Figure 1-Okanagan experimental sprayer, the prototype of concentrate sprayers in British Columbia.

'The first Canadian work on concentrate spraying in deciduous orchards was mentioned briefly by Marshall in 1946 (35). The following year Marshall and Miles (36) described experiments in applying spray concentrates with five types of mobile machines. Although none of the machines was satisfactory the authors wrote; "there is little reason to doubt that conventional, high-pressure sprayers will shortly be supplanted by light, high-speed equipment". After listing what 
they considered the necessary features of a light, "automatic" sprayer, they mentioned that an experimental machine embodying these features was to be built at once. In a paper presented to the Seventh Pacific Science Congress in 1949, Marshall and Miles (38) described the performance of the Okanagan experimental sprayer (Fig. 1). It had proved so successful that it was serving as a prototype for two commercial concentrate sprayers being built in British Columbia.

Progress in concentrate spraying in Ontario and the Maritime Provinces of Canada, and also in Great Britain, Europe, and the Antipodes, has been discussed by Marshall (39). In Australia and New Zealand, where machines of Canadian design are now manufactured, the method is being rapidly adopted; but in the other areas just mentioned, acceptance is slower. The same applies to the western fruit growing areas of the United States. So far, little if any work on concentrate spraying has been done in South Africa.

\section{TYPES OF SPRAYERS}

Concentrate sprayers may be grouped in three types:-

1. Air nozzle manually operated (two-man machines).

2. Air nozzle or nozzles mechanically oscillated or rotated.

3. Air nozzle fixed.

Types 2 and 3 are available for one-side and two-side spraying. They are operated by one man, the tractor driver. Some manufacturers of large, highvolume sprayers claim that, by fitting nozzles with very small orifices, their machines become concentrate sprayers. As a rule such sprayers are equipped with low-pressure, centrifugal pumps that, with the type of nozzle generally used, are incapable of atomizing the spray liquid to the degree necessary for safe and efficient concentrate spraying. Furthermore, the blowers of the large machines produce an air stream of high volume but relatively low velocity, and such an air stream is of no value in reducing the size of the spray droplets unless the spray stream is forced directly into the air stream; generally that is not the case.

Experience of the last ten years in British Columbia has shown the logic of designing spray equipment to meet specific needs. There is no point in using an expensive, two-ton machine to do a job that can be done well by a relatively inexpensive machine of less than half the weight.

The concentrate sprayers now being manufactured in this province have fixed air vents, and most of them are one-side machines. They look puny indeed beside machines of the high-volume, air-blast type, many of which are over twice as heavy and four times as powerful as the locally built ones.

Concerning sprayer design, Hoare (31) summed up the situation in these words: "The world problem of spraying is contained in a room through which you enter by three consecutive doors the keys of which are held separately by the engineer, the chemist and the biologist, . . . the writer believes that, at the moment [1952], the closed door which requires opening first is under the control of the engineer ...". A number of years previously Davies and SmytheHomewood (17) had written: "Manufacturers ... have done much to introduce improved machinery but the amount of time they can devote to research is necessarily limited and so they tend to produce what is demanded by the growers". To some extent that observation still holds; but the type of spray 
applicator demanded nowadays in many fruit growing districts is conditioned to a considerable degree by advertising, by the adequacy of local research in spraying techniques, and by the current preoccupation with super-powered and supersized equipment of all kinds.

Davies and Smythe-Homewood mentioned that it is logical to carry out research in sprayer design in the heart of a fruit growing district where the engineer can have the advantage of close collaboration with entomologists, chemists, and technical advisers as well as fruit growers. It was under such conditions that concentrate sprayers were developed in British Columbia (Fig. 2). As reported by Marshall (39), a group of entomologists, chemists, and horticulturists and, later, an agricultural engineer, teamed with machinists in designing spray equipment to meet a specific need. The available information on spray chemicals, how they are formulated and how they function, was taken into account, as well as that on methods of atomization, and types of blowers and gasoline engines. Abrasion and corrosion-resistant materials were examined, and consideration given to the most effective droplet sizes. Good horticultural practice, and the economics of the fruit industry were kept in mind. The outcome was a one-man sprayer capable of doing what the British Columbia fruit growers wanted at a price most of them could afford.

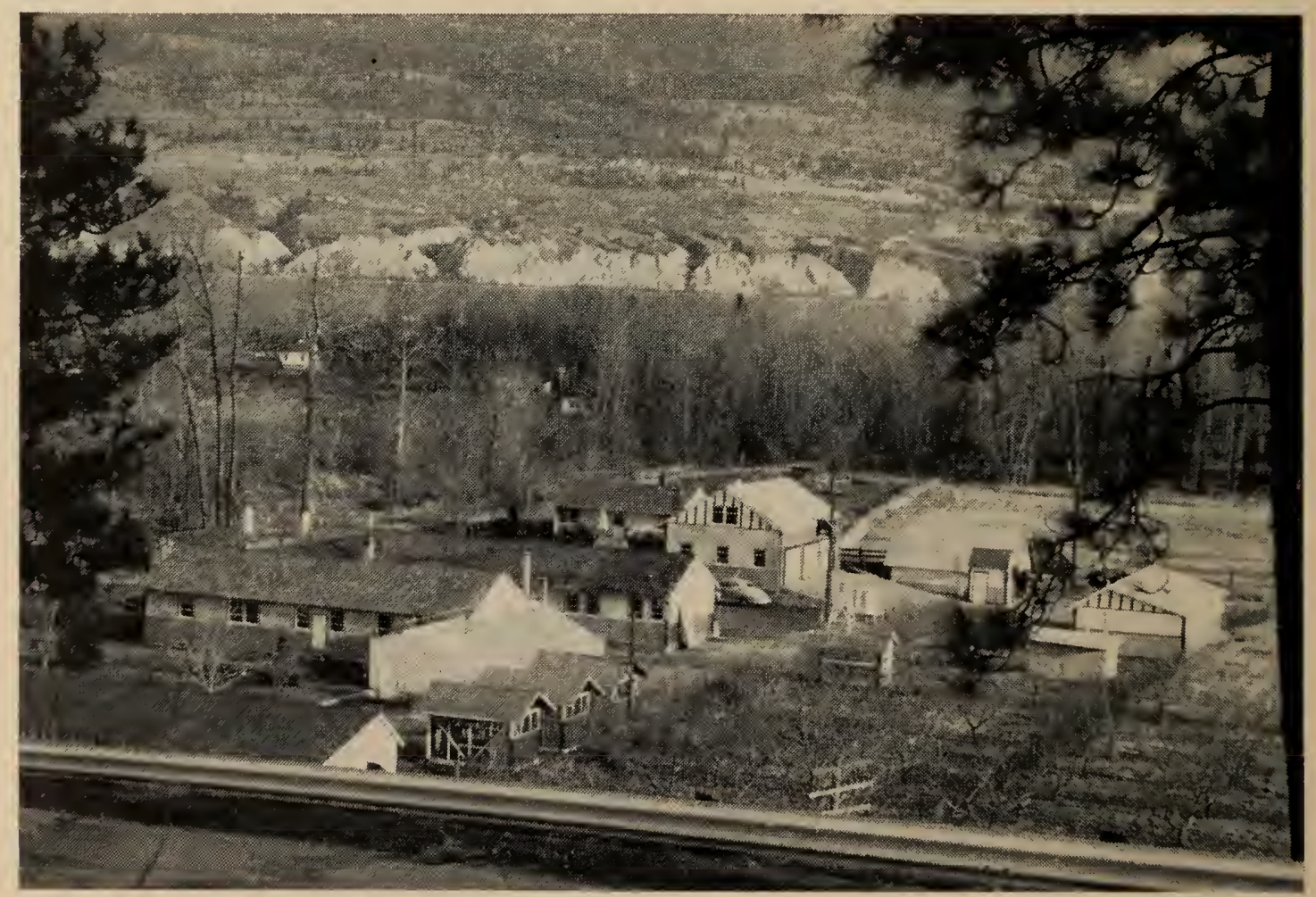

Figure 2-Entomology Laboratory, Summerland, British Columbia.

Since the introduction in 1949 of the first commercial concentrate sprayers by two British Columbia manufacturers, and one United States manufacturer, there have been many improvements in design (Fig. 3). The weight of the single-side machines has remained under one ton, but they have become lower and more carefully streamlined in order to pass more readily beneath overhanging branches (Fig.4). They are available with either two-wheel or four-wheel mounting. Although more expensive, the latter is preferred because of lighter draft, less tendency to compact the soil, and more nearly uniform spray application when travelling over rough ground. 
One of the more troublesome problems in concentrate spraying has been corrosion and scaling of steel tanks, and consequent plugging of screens and nozzles. The problem has been largely overcome by using stainless-steel or fiberglass-plastic tanks.

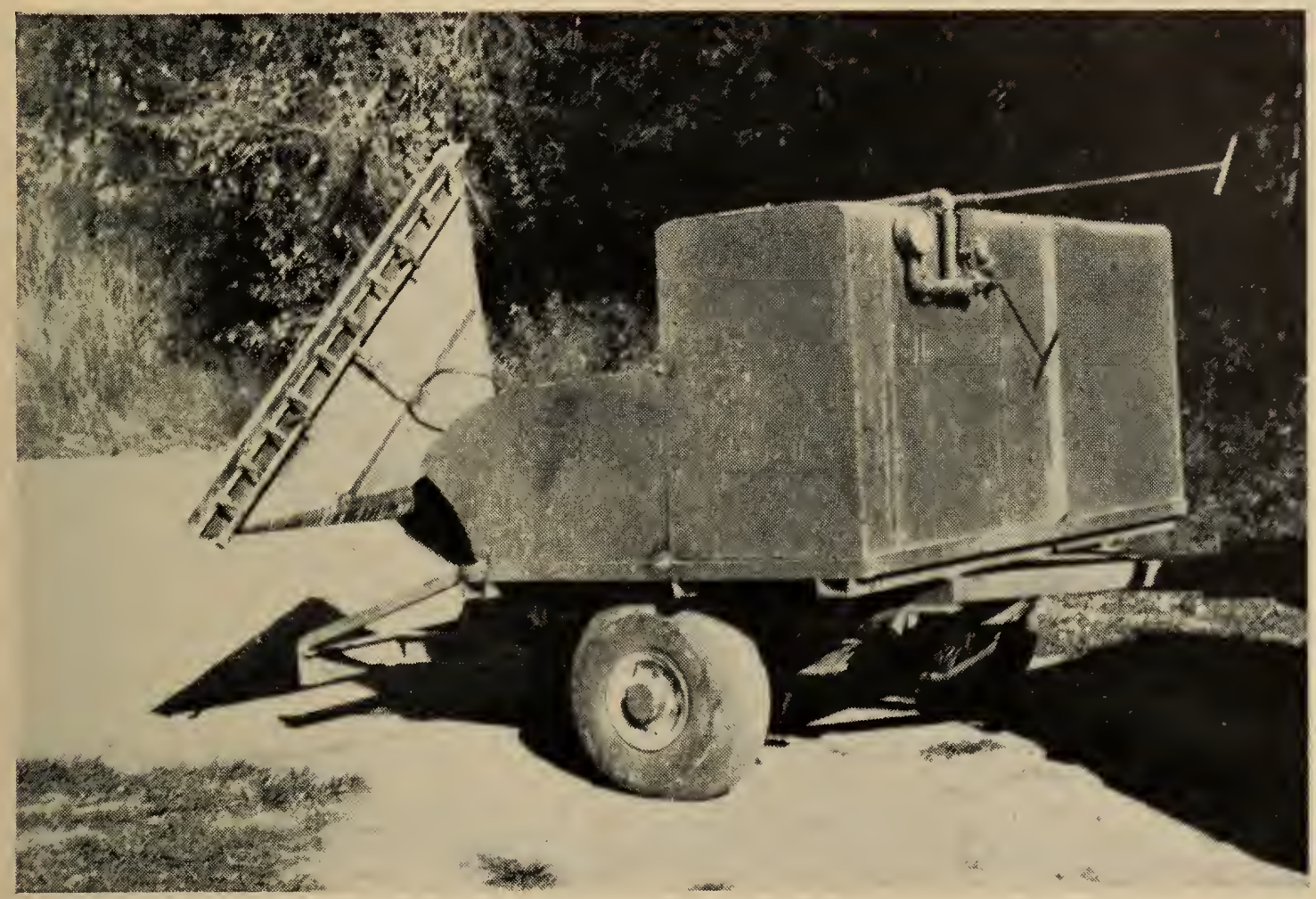

Figure 3-The first concentrate sprayer commercially built in British Columbia, in 1949.

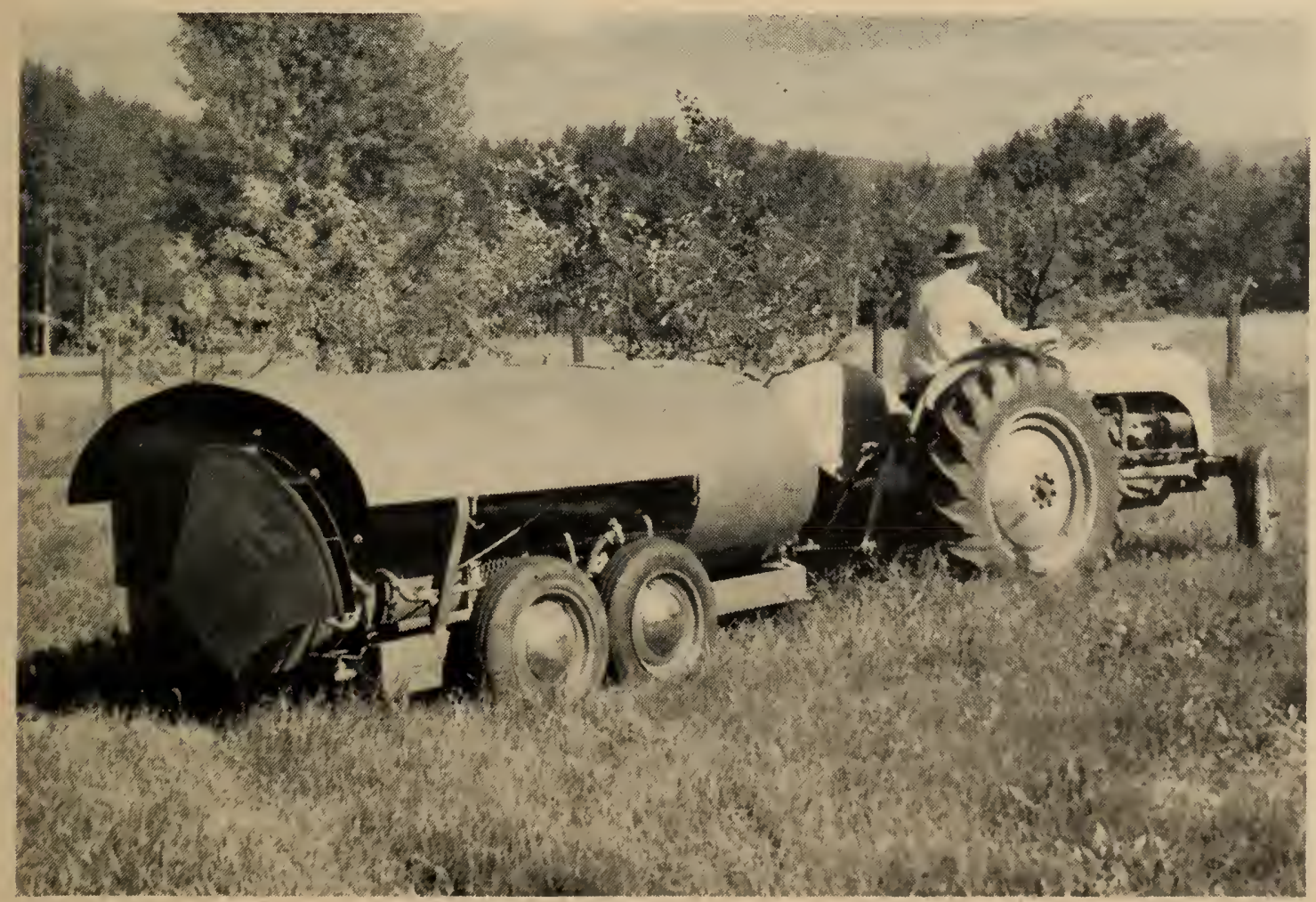

Figure 4-Turbine-type, one-side concentrate sprayer, 1955 model, made in British Columbia. 
One of the British Columbia machines has a turbine-type blower producing a linear-flow air stream of 6,500 to 7,000 cubic feet per minute at a velocity of 105 to 120 miles per hour. The other has an axial fan that moves about 21,000 cubic feet of air per minute at 93 miles per hour (Fig. 5). When hauled at the rate of 1 mile per hour both machines have given adequate penetration of full-foliaged, well-pruned fruit trees up to 30 feet in diameter and 15 to 18 feet high.

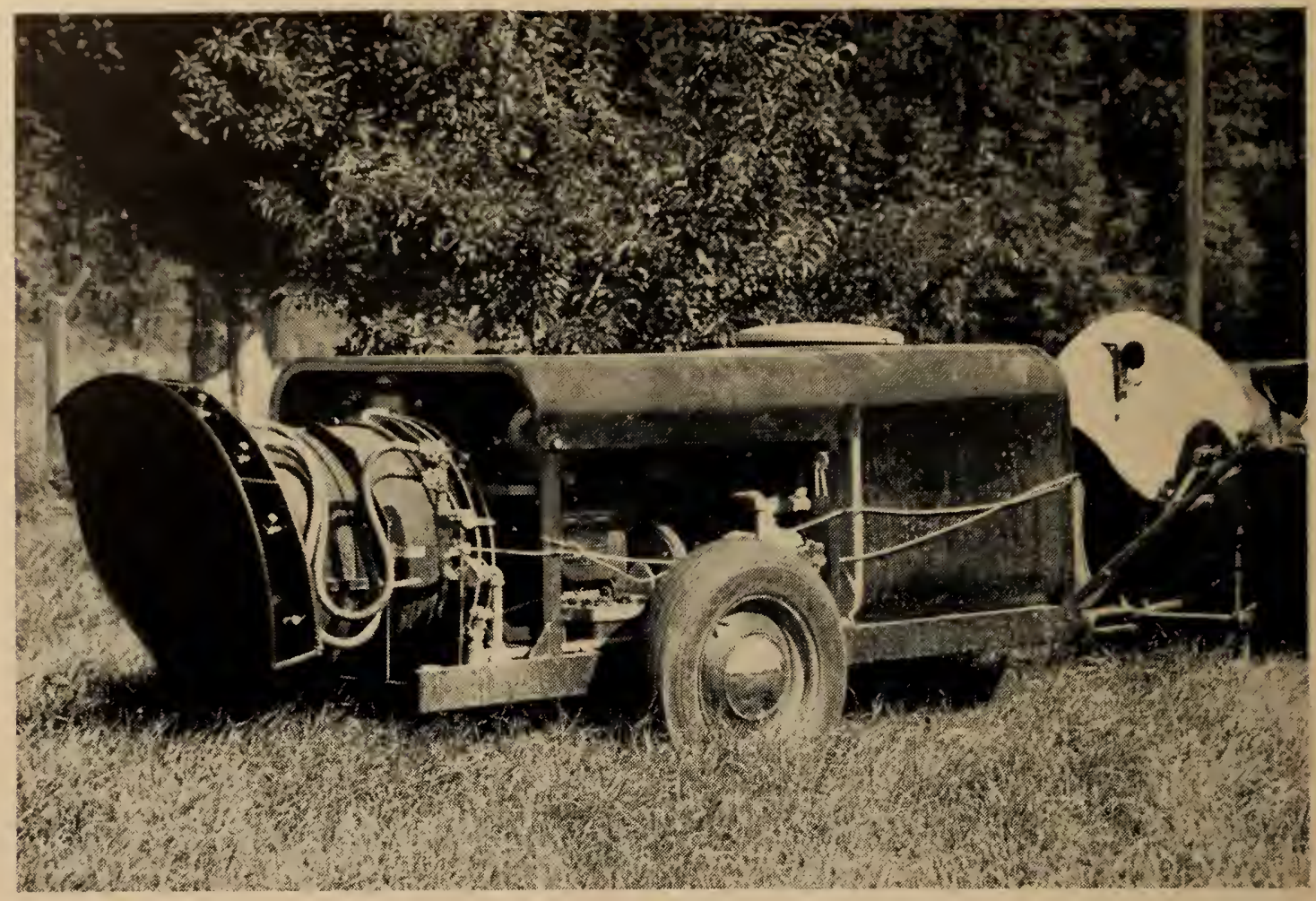

Figure 5-Axial-flow, one-side concentrate sprayer, 1956 model, made in British Columbia.

Because of the importance of adequate atomization, piston-type, highpressure pumps are used on both Canadian-built machines in preference to less expensive, low-pressure, centrifugal pumps or to gear pumps. The spray nozzles are of the hollow-cone, swirl type and are fitted with orifice discs and swirl plates made of that exceedingly hard substance sintered tungsten carbide. One of the manufacturers has been fitting the pressure-relief valve with tungsten carbide inserts at the points of greatest wear. Although both machines are equipped with air-cooled engines, the performance of an experimental model fitted with a liquid-cooled, overhead-valve engine has been such as to suggest that liquid-cooled engines may shortly be optional. In New Zealand light, liquid-cooled, overhead-valve automobile engines, of British manufacture, have been giving satisfactory results with the turbine type of Canadian concentrate sprayer.

To meet the requirements of some operators of large acreages "two-side" machines are being built by both of the British Columbia manufacturers. Unlike the "single-side" unit, which is generally operated somewhat beneath the overhanging branches, the two-side machine must travel midway between the two rows of trees. Consequently, unless the rows are less than 30 feet apart, or the trees are of modest size, or are exceptionally well pruned, adequate 
penetration of heavy foliage is more difficult to attain. Evidently somewhat more than double the power input is necessary for equivalent penetration of foliage (Figs. 6 and 7 ).

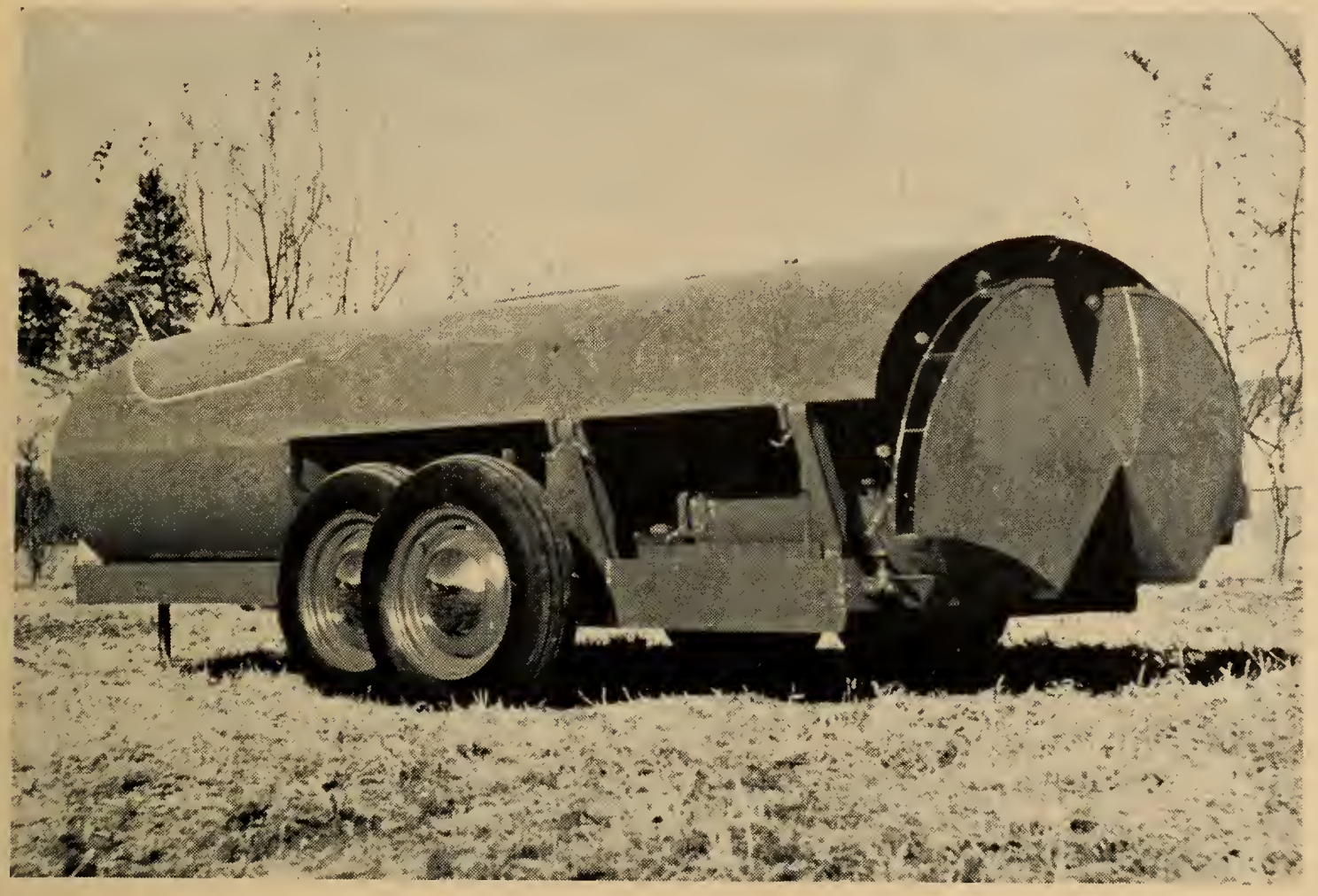

Figure 6-Turbine-type, two-side concentrate sprayer with stainless steel tank, 1956 model.

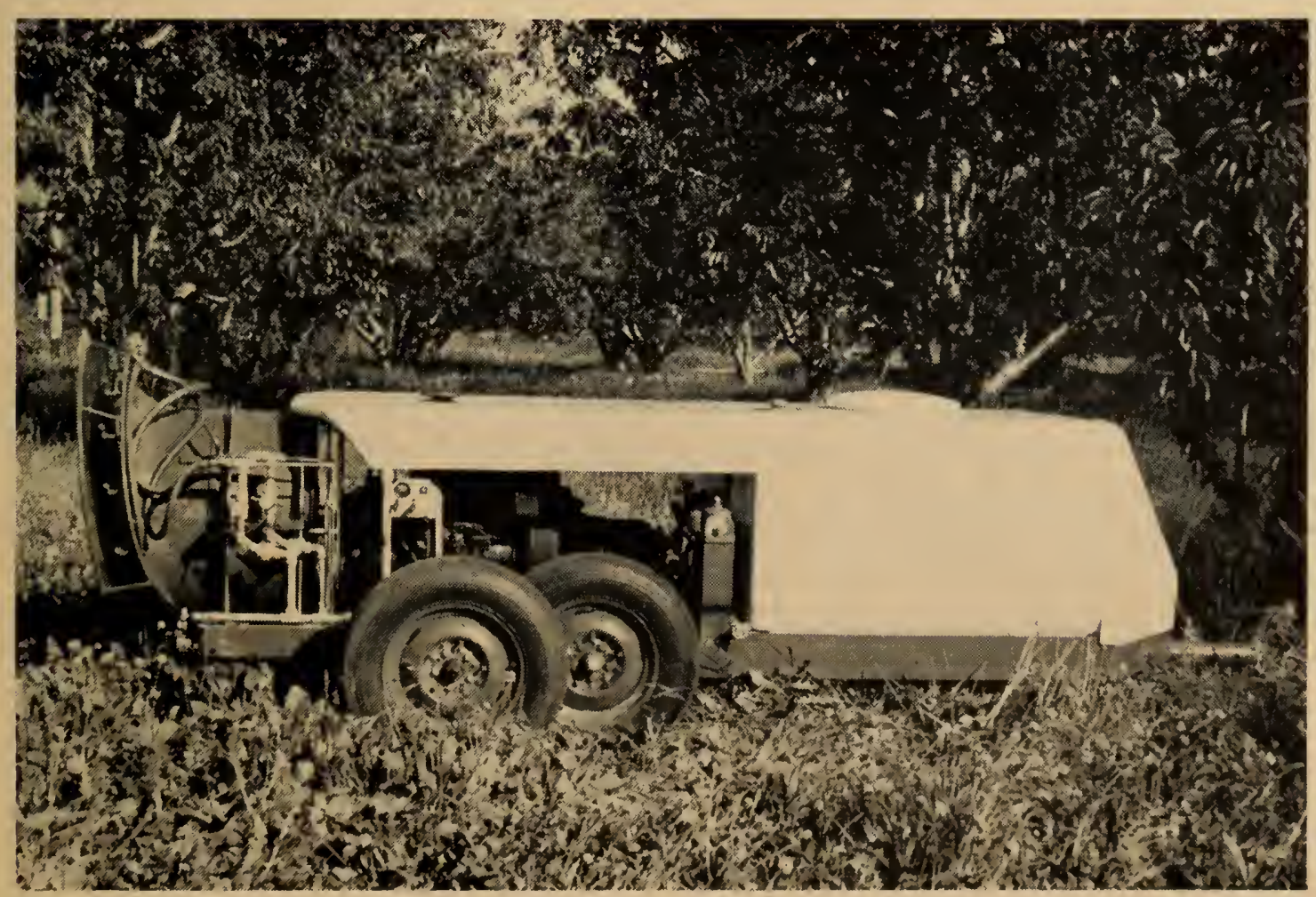

Figure 7-Axial-flow, two-side concentrate sprayer with fiberglass-plastic tank, strainer and hood, 1956 model. 


\section{EFFECTIVENESS OF CONCENTRATE SPRAYING}

Courshee (15) sums up orchard spraying techniques thus: "As yet no method and program has been shown to be successful on a sufficiently widespread scale to be certain that it works under all conditions". Whether light, concentrate sprayers will eventually displace heavy, high-volume machines entirely is, of course, debatable. But, as greater attention is paid to the development of less phytotoxic spray chemicals, as more information becomes available on sprayer design, and as more regional and local research is undertaken to evaluate spraying procedures, doubtless the logic of using minimum quantities of water to distribute spray chemicals will be ever harder to dispute.

Marshall and Miles (36) conducted experiments in British Columbia to determine whether either wet or dry dusting is as effective against orchard pests and diseases as concentrate spraying. They concluded that dusting was inadequate. Evidently a similar conclusion was reached at Cornell University, where Pratt (55) reported on an investigation of dusting versus concentrate spraying begun in 1940 .

That there are decided differences of opinion on the effectiveness of concentrate spraying, even within a limited area, is shown by reports from the State of New York. Glass and Lienk (23) say: "Our data indicate that there is no saving in material, and further, there is some indication that more material may be required to get the same results that are obtained with dilute spraying". But Burrell (13) points out that concentrate spraying is gaining acceptance in New York State because of its savings in man- and machinehours.

In a study of the cost and effectiveness of spraying methods, Von Oppenfeld et al. (63), also of New York, concluded that, regardless of type of machine, pest control was inferior on trees over 20 feet high. Poor control was frequently associated directly with excessive rate of travel. In other instances it was indirectly associated with a very rapid output of spray liquid; a high output tended to induce a hurried job. Concentrate spraying was the least expensive method.

Garman (22) mentions that small, cheaply constructed concentrate sprayers have proved unsatisfactory, but well-designed mist blowers have given just as good results as hydraulic, high-volume machines in Connecticut. $\mathrm{He}$ does not favor automatically oscillated or rotated, air vents, considering that they add little to the effectiveness of a sprayer although they complicate its design.

In England, as in North America, there are differences of opinion on concentrate spraying. Beskine (5), for example, states that "single-shot", i.e., fixed air-vent spraying, is too wasteful and expensive. He favors the manually operated nozzle of the two-man machine as developed in Holland and Great Britain. Kearns (34), on the other hand, thinks that machines with "guided nozzles" are of debatable value, the ultimate aim being the development of fully automatic spray machinery. He emphasizes that growers who wish to use automatic applicators should see that their trees are kept to a size within the capacity of their spray equipment.

It is pointless to expect that a light, concentrate sprayer powered, for example, with a 25-horsepower engine will be capable of producing adequate spray coverage in apple trees 25 feet high and 35 or 40 feet in diameter. That is a job for a large, high-powered machine and, preferably, for high-volume application. When such very large trees are poorly pruned, or when their branches sweep the ground, the problem is doubly difficult; for it is under such 
conditions that apple scab and many insects and mites flourish best, and spray penetration is poorest. In Michigan, Mitchell (41) has repeatedly stressed to the owners of concentrate sprayers the importance of good pruning. He reported no reduction in yield from adequately pruned trees, but, as compared with high-volume spraying, a reduction in the amount of spray chemicals in concentrate spraying, and lower cost of spray application.

Using equal quantities of insecticide per acre, Waddell and McArthur (64) compared spray deposits on British Columbia apple trees from thorough highvolume, hand-gun spraying and those from concentrate spraying with a 25horsepower turbine machine. The trees, 25 feet in diameter and 20 feet high, were of two types; some were pruned, some not pruned. Waddell and McArthur summarized thus: (a) In the dormant period, oil deposits in the nonpruned trees were equal to those in the pruned trees, whether hand-sprayed or concentrate-sprayed. (b) With an equal quantity of oil per acre, concentrate spraying produced treetop deposits of dormant oil four times as great as hand spraying. (c) After the foliage had fully developed, treetop deposits of DDT from concentrate spraying were about 50 per cent lighter in non-pruned trees than in pruned trees; with the hand spraying there was no difference. (d) Despite the reduction in treetop deposits of DDT from concentrate spraying in non-pruned trees, the deposits were, nevertheless, as heavy as from hand spraying with an equal per-acre quantity of DDT. The authors concluded that concentrate spraying is a more efficient means of applying spray chemicals than hand spraying, and that concentrate spraying emphasizes the importance of good pruning.

Cutright (16) found that the control of orchard mites in Ohio was as good from an acaricide suspension applied at 100 gallons per acre as at 1,000 gallons. Experimental work reported by Marshall and Miles (38), later work at Summerland (unpublished), and commercial results have shown that an efficient concentrate sprayer, well operated, provides as good control of the most important pests of British Columbia orchards as commercial high-volume, hand-gun spraying. Among those pests are the European red mite, Metatetranychus ulmi (Koch); the two-spotted mite, Tetranychus telarius (L.); the yellow spider mite, Eotetranychus carpini (Oudms.); the brown mite, Bryobia arborea M. \& A., formerly not distinguished from the clover mite, Bryobia praetiosa Koch; the McDaniel mite, Tetranychus mcdanieli McG.; the codling moth, Carpocapsa pomonella (L.); the San Jose scale, Aspidiotus perniciosus Comst.; lygus bugs, the peach twig borer, Anarsia lineatella Zell.; the apple aphid, Aphis pomi DeG.; the woolly apple aphid, Eriosoma lanigerum (Hausm.); the black cherry aphid, Myzus cerasi (F.); and the pear psylla, Psylla pyricola Foerst.

On the other hand, the control of apple scab and of apple powdery mildew is not so good as would be expected from the high deposits of fungicides that are obtained. Pratt (56) noted that, in New York State, the control of apple scab with an efficient concentrate sprayer was as good as with hand spraying, but the fungicide deposits were much higher, hence evidently less efficient. Presumably the type of spray deposit most effective in controlling fungus diseases differs from that needed to control insects and mites. This point is discussed further under the heading "Surface-active Adjuvants".

Relatively little work appears to have been done on concentrate spraying in citrus groves. In Florida, Griffiths et al. (26) compared insect control on orange trees from high-volume spraying and concentrate spraying ( $\frac{1}{8}$ of high-volume). Control of rust mites and scale insects was equally good by the two methods. In Australia, on the other hand, Mr. C. Brickhill, Department of Agriculture, New South Wales, (private communication) found that an efficient concentrate sprayer of the turbine type was measurably less effective 
than high-volume spraying in controlling the California red scale, Aonidiella aurantii (Mask.) with oil application. Brickhill's findings have some support in experiments in British Columbia against the San Jose scale, Aspidiotus perniciosus Comst., on apple. There is evidence that heavy infestations of that pest may be more effectively dealt with by applying 150 gallons of spray liquid per acre from four sides of each tree than 75 gallons from two sides, the amounts of toxicant per acre being the same. Presumably that is because it is difficult to wet well-protected insects in the larger crotches of the trees. Light to moderate infestations of the San Jose scale, however, have been adequately controlled at the smaller dosage.

\section{SPRAY INJURY}

Critics of concentrate spraying generally disapprove of it on two counts: It is not sufficiently effective; it is too likely to cause spray injury. Perhaps the first criticism arises from lack of information. It is not generally appreciated that many of the so-called concentrate sprayers, or conversion or attachment units now in use, are incapable of applying concentrate sprays (less than 75 gallons per acre) safely or uniformly. They were evidently manufactured and sold on the assumption that concentrate spraying merely means decreased output of spray liquid, and correspondingly increased concentration of spray chemical; and that almost any makeshift equipment capable of projecting air and liquid simultaneously can be called a concentrate sprayer. Fortunately those misconceptions are being corrected; but a certain amount of poor equipment is still being sold to growers who are more concerned about low cost than efficiency.

As for spray injury the evidence is not entirely one-sided. Spray chemicals that have a tendency to be phytotoxic may be particularly likely to cause injury at high concentration. Certainly they should not be applied by so-called concentrate sprayers having poor atomization, faulty distribution of spray liquid in the air stream, inadequate blowers, or inadequate agitation. But the best of today's concentrate sprayers, properly operated, are capable of handling any of the spray chemicals in general use for high-volume spraying. There is another consideration: in view of the wide selection of acaricides, insecticides, and fungicides now available, it is questionable whether it should be necessary to use any that are known to be hazardous to the tree, to the operator, or to the consumer of the fruit.

Let us look now at the other side of the evidence. Ingerson (33), referring to the effects of standard spray schedules, reported less injury from concentrate spraying than from dilute spraying. Mitchell (41) mentioned that fruit russetting decreased with increased concentration of spray chemicals, and Harley (28) agreed. Moore (44) found that undiluted lime-sulphur, applied to apple trees as very fine droplets, caused no injury; applied as a spray of larger droplets, it caused pronounced injury.

It may seem remarkable that lime-sulphur, that excellent but caustic insecticide-acaricide-fungicide of long standing, should be more likely to cause injury to fruit or foliage if applied highly diluted than highly concentrated, at the same per-acre dosage. Evidently it is entirely a matter of the rate of drying of the spray deposit; the sooner the spray deposit dries the less the likelihood of injury by lime-sulphur. A tree drenched by high-volume spraying takes considerably longer to dry than one that has been sprayed by the fine mist of a concentrate machine. The observation that the concentration of lime-sulphur may have little to do with spray injury was made in British 


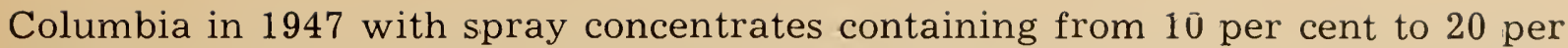
cent lime-sulphur of $32^{\circ}$ Be. gravity, compared with high-volume spraying with one per cent lime-sulphur; that observation has been verified repeatedly. Needless to say, concentrated lime-sulphur should never be applied to wet trees.

\section{FACTORS AFFECTING THE EFFICIENCY OF SPRAYERS}

\section{Air Stream}

Concentrate sprayers are equipped with either of two general types of blowers, axial-flow or centrifugal. Axial-flow blowers vary in form from few-bladed to multibladed, and from what is commonly considered a typical fan to an air turbine. An axial-flow blower delivers the air parallel to its axis or shaft; consequently, if the air stream is directed into the double vent of a two-side sprayer, the characteristics of the two halves of the air stream are similar. As the number of blades is increased, and the clearance between rotor and casing diminishes, the characteristics of the air stream change. Static pressure increases and turbulence decreases until, with the multibladed air turbine, what has been referred to as a "hard", or linear-flow, air stream is produced. Experiments at Summerland have indicated that such an air stream penetrates heavy foliage better than a turbulent air stream of equal volume.

Centrifugal blowers are characterized by the fact that they deliver the air radially. Since the air comes off the tips of the blades there is a tendency to pulsation and, with two-sided blower scrolls, to an uneven delivery; the air tends to travel upwards on one side of the machine and downwards on the other, in the direction of the blower's rotation.

Opinions differ as to the most desirable air velocity and air volume for applying spray concentrates. When spraying to one side in a mature 30 -foot planting of apple trees, with an output of 12,000 to 20,000 cubic feet of air per minute, a minimum air velocity of 90 miles per hour appears to be desirable. With an output of only 7,000 cubic feet of air per minute the minimum velocity, evidently, should be at least 110 miles per hour, and the air stream should be of the linear-flow type.

Some workers, notably in California, have expressed the opinion that an efficient spray job demands the complete displacement of the air within the outline of the tree. Akesson (1) has calculated that, at a speed of one mile per hour, an air output of 5,000 cubic feet per minute is required for 10 -foot trees, 20,000 cubic feet for 20 -foot trees, and 50,000 cubic feet for 30 -foot trees. Such is the reasoning behind the use of the huge, high-volume, air-blast sprayer of which Beskine (5) is critical. As he puts it: "They are designed to saturate the whole of the atmosphere around the trees. This may appear impressive to the uninitiated but it is not,... . Effective blast spraying can be obtained with a modest expenditure of fuel, a reasonably small engine, and little wastage of chemicals". Byass (6) agrees with Beskine. Experiments in Great Britain, he writes, indicate that a high-volume, low-velocity air stream is not necessarily better than a low-volume, high-velocity air stream in producing good spray coverage. The Summerland work supports Beskine and Byass; it is discussed later under the heading "Rate of Travel".

\section{Blower Scroll and Air Vent}

The design of the air vent plays an important part in the performance of an orchard concentrate sprayer; but air vents vary so widely in shape and in dimensions that more research is apparently needed in relating type of air 
verit to type of blower. Some machines, e.g., Kiekens Whirlwind (Holland) ${ }^{1}$ and R.S.M. (Denmark)², employ a stationary air vent made up of several circular orifices, one above the other. An American machine (Lawrence Mist-o-matic) ${ }^{3}$, uses three circular vents mounted on a rotating head. Another American machine (Iron Age)t uses a fixed "key-hole" type of air vent, the middle part with a wider cross section than the ends; a Canadian machine (Turbo-Mist)" has a somewhat similar air vent. Seen from front or rear, most air vents are of the arc-of-circle type, but a very efficient concentrate sprayer, the Hardie Orchard Mist', is fitted with a projecting rectangular air vent eight feet long and four inches wide, that is carried at a 45-degree angle to the vertical. The Turbo-Mist of Australia ${ }^{7}$ and New Zealand ${ }^{8}$ uses a similar but smaller air vent, as does the Air Mist of Australia ${ }^{9}$.

It has been claimed that good penetration of foliage by an air stream is assured by an oscillating air vent, as on the American-made Myers ${ }^{10}$ concentrate sprayer, a machine on which the entire blower scroll is oscillated through an arc of some 30 degrees. The Myers machine, as do most other concentrate sprayers, delivers air at right angles to the line of travel; but the Kiekens Whirlwind, which uses more highly concentrated spray mixtures, delivers the air at a distinct angle to the rear. The manufacturers claim that, otherwise, there would be a risk of overspraying the lower parts of the trees. The Trump concentrate sprayer (Canada) ${ }^{11}$ directs the air stream at about a 10-degree angle to the rear.

Referring to the experimental concentrate sprayer developed at Cornell University, Parker and Pratt (47) emphasize the importance of directing the air stream at approximately a 45-degree angle to the vertical. They found that a horizontal delivery tended to drive the outer branches backwards against the inner ones, whereas a vertically directed air blast resulted in excessive under-leaf spray deposition. They contended, furthermore, that the spray should be directed exactly at right angles to the line of travel. Marshall and Miles (38), arrived, independently, at the same conclusions. Their Okanagan experimental sprayer had, in fact, air delivery very similar to that of the Cornell machine except that the volume of air was little more than one third as great. On the other hand, the Okanagan sprayer was designed to operate at a speed of one mile per hour in a mature 30-foot planting, whereas the Cornell one was operated at two to three miles per hour. The actual volumes of spray-laden air to which the trees were subjected were, therefore, fairly similar.

\section{Liquid Manifold}

In the early days of air-blast spraying, hydraulic machines with fixed air vents were usually fitted with multi-nozzled liquid manifolds. Although, in those days, they were a nuisance from the standpoint of nozzle obstruction, multi-nozzled manifolds, with small disc orifices, were considered necessary for adequate atomization. The work of Davies and Smythe-Homewood (17),

${ }^{1}$ Kiekens-Whirlwind-Holland, Bommelweg 43-44, Wadenoyen, Holland.

${ }^{2} \mathrm{R}$. Sigvardt Motorfabriken, Orehoved, Denmark.

${ }^{3}$ Lawrence Aero-Mist Sprayer Company Incorporated, Greenfield, Massachusetts, U.S.A.

${ }^{4}$ A. B. Farquhar Division, Oliver Corporation, York, Pennsylvania, U.S.A.

sOkanagan Turbo Sprayers Limited, Penticton, B.C., Canada.

${ }^{B}$ Hardie Manufacturing Company, Hudson, Michigan, U.S.A.

${ }^{7}$ Ronaldson Brothers \& Tippett Limited, Ballarat, Victoria, Australia.

${ }^{8}$ Fruit Growers Chemical Company, Port Mapua, Nelson, New Zealand.

${ }^{9}$ Metters Limited, Mile End, Adelaide, Australia.

${ }^{10}$ F. E. Myers \& Brothers Company, Ashland, Ohio, U.S.A.

${ }^{11}$ Trump Sales Limited, Oliver, B.C., Canada. 
Taylor (62), and French (19) had shown, however, that within practical limits the size of the orifice of a swirl nozzle has little or no bearing on the degree of atomization of the spray liquid. The point was investigated by Messrs. D. B. Waddell and J. M. McArthur (unpublished work) at Summerland. They fitted an experimental turbine sprayer with a ten-nozzle manifold, and, by blocking off certain nozzles and increasing the orifice diameter of others, examined various nozzle arrangements. They concluded that a three-nozzle arrangement was capable of producing an effective spray pattern. Since the cost of a three-nozzle manifold is considerably less than that of a multi-nozzle one (tungsten carbide swirl plates and orifice plates are expensive), and since, because of large orifices in two of the three nozzles, the three-nozzle manifold is less likely to give trouble from blockage, it is now standard equipment on one of the Canadian-built concentrate sprayers. The other sprayer is fitted with a five- or six-nozzle manifold.

In spraying large fruit trees it is important that the amount of spray liquid directed at the upper branches be considerably greater than that at the lower branches-according to Brann (10), five to six times as much and, according to Moore et al. (43), perhaps 10 times as much. In order to ensure adequate treetop deposits, therefore, the upper two nozzles of the three-nozzle manifold have larger orifices than the lower ones. In applying 75 gallons of spray liquid per acre at a pressure of 300 pounds per square inch, the orifice diameter of the topmost nozzle, (dealing with the upper branches of the near side of the tree) is 0.094 inch; that of the center nozzle (dealing with the middle branches of the near side of the tree and the upper branches of the far side), 0.125 inch; and that of the bottom nozzle, 0.050 inch. In applying 50 gallons per acre the respective orifice diameters are $0.050 \mathrm{inch}, 0.094 \mathrm{inch}$, and $0.040 \mathrm{inch}$. The nozzles are fitted with standard swirl plates with two orifices, each orifice $1 / 16$ inch in diameter and inclined at an angle of 45 degrees to the face of the plate.

\section{A:omization of Spray Liquid}

In the days of high-volume spraying, whether with spray gun or air-blast machine, little thought was given to the droplet spectrum. Since the trees were sprayed to dripping, the important point was an adequate distribution of the spray liquid; large droplets, or a wide variation in droplet size were not necessarily detrimental. It is otherwise with concentrate spraying. If sprayed to dripping, highly concentrated insecticide or fungicide mixtures may injure fruit or foliage, so that it becomes a matter of covering the sprayed surfaces as completely as possible short of coalescence of the droplets to cause drip, or "run-off". Unless modified by the presence of a surfactant, as discussed later, coverage of that kind requires very small droplets, the more nearly uniform in size the better. Goossen (24) has mentioned that a threefold increase in drop diameter produces an equivalent decrease in coverage. Droplets 270 microns in diameter, as in high-volume spraying for example, cover only one third as much of leaf or fruit as an equal volume of liquid in the form of 90 -micron droplets, as in concentrate spraying: Goossen and Eue (25) have defined the reduction of a spray liquid to droplets of less than 150 microns in diameter as atomization.

Kearns (34) and Edwards and Ripper (18) have pointed out that, with low-volume sprays, the smaller the droplet size the better the penetration of dense foliage. Yeomans and Rogers (66), quoting Sell (58), state that the maximum penetration of foliage is accomplished by maintaining a low efficiency of deposition on the nearer parts of the tree: "For penetration through the $95319-3$ 
lower branches the particle size should be reduced to less than 50 microns mass median diameter". But penetration is only part of the story. If the droplets are too fine they will not impinge on the surface to be protected. According to Potts (54): "A field of resistance surrounds all objects... and repels droplets smaller than approximately 30 microns in diameter". For concentrate spraying with ground equipment he gives an optimum droplet size range of 30 to 80 microns. Beskine (5) claims that 50 microns is the minimum droplet diameter for effective work. Garman (22) mentions that, for mist-blowers, droplet size should be from 50 to 100 microns. He notes that smaller droplets do not impinge readily, and larger droplets fall out too quickly. Recognizing the undesirability of ultra-fine droplets, Goossen and Eue (25) point out that a decrease in the size of the droplets must be accompanied by an increase in the velocity with which they leave the machine; otherwise they will not come to rest where intended.

Working at the Summerland laboratory with a 25-horsepower, turbine, concentrate sprayer, Mr. D. B. Waddell (unpublished work) found that, although 98 per cent of the spray droplets were below 100 microns in diameter, the remaining two per cent constituted about 50 per cent of the spray liquid. One of the most important jobs in the development of concentrate spraying is to reduce the relatively few large droplets to more efficient dimensions, or to increase their covering capacity in some other way. Some British and European sprayer manufacturers claim to have solved the problem by mechanical means. One overseas machine, for which uniformly fine atomization is claimed, has been examined at Summerland, but only with liquid output of 10 to 15 gallons per acre did it achieve exceptionally fine atomization. Consequently, its use appears to be restricted to the application of highly concentrated liquid pesticides; and such formulations are generally more prone to cause plant injury than the wettable powders that are favored in British Columbia. On the other hand, several overseas manufacturers indicate that it is feasible to get adequate spray coverage from exceedingly fine mists without necessarily overspraying branches close to the machine, and hence running undue risk of injury. The experimental work at Summerland has not yet shown how that can be accomplished. This point is discussed later under the heading "Surface-Active Adjuvants".

The reduction of a sprav liquid to droplets fine enough for concentrate spraying may be accomplished by projecting the liquid at low speed into rapidly moving air or other gas, or by projecting the liquid at high speed into relatively slowly moving air. Atomization of the first type has been achieved with compressed air, and with high-pressure steam. French (19) wrote that such methods produce smaller droplets than other types of atomization. Air at a pressure of 20 pounds per square inch, for example, produced droplets averaging 55 microns in diameter; at 80 pounds per square inch, the droplets averaged 35 microns in diameter. Steam generators such as the Besler ${ }^{12}$ of the Second World War, are capable of reducing liquids to an extremely fine state of subdivision, to produce true fogs. With such equipment, later adapted to apply pesticides, the size of the spray droplets can be modified by the simple adjustment of a thermo-regulator. In experiments at the Summerland laboratory between 1946 and 1949, atomization by steam proved to be a somewhat more complex and more expensive procedure than atomization by hydraulic pressure. Steam atomization did not come into general favor with the fruit growers.

Compressed-air atomization, as mentioned by French (19), was used between 1930 and 1932 in spraying California vineyards with quantities of liquid as low as two to four U.S. gallons per acre. Recently there has been a

${ }^{12}$ Besler Engineering Corporation, Emeryville, California, U.S.A. 
revival of this procedure in Great Britain with, it is claimed, excellent results. The compressed-air method of atomization has not yet been examined at Summerland. The subject is mentioned further under the heading "Type of Nozzle".

In concentrate spraying the usual methods of atomization are by hydraulic pressure, or by a combination of hydraulic pressure and high-velocity air. Hydraulic pumps may be grouped in three categories: rotary, diaphragm, and piston pumps. The first two types usually operate at relatively low pressures (up to about 100 pounds per square inch); piston pumps are generally used when higher pressures are required. Most rotary and diaphragm pumps do not develop sufficient pressure to produce the fine droplets necessary in concentrate spraying. That shortcoming however, may be minimized or overcome by the use of a special nozzle, by an exceptionally high-velocity airstream, or, perhaps, by the addition of a surfactant to the spray concentrate. According to French (19), air moving at 125 to 150 miles per hour exerts a considerable shearing action on a spray liquid. Experiments at Summerland suggest that, with conventional nozzles, the air velocities developed by most concentrate sprayers (less than 150 miles per hour) are too low to play a significant role in atomizing the spray liquid.

Another device to improve atomization is the "reversed" nozzle. As pointed out by Akesson (1) the degree of atomization produced upon introduction of a liquid stream into an air stream is a function of the difference in velocity, so that the greatest break-up of liquid occurs when the spray nozzle is directed against the air stream. A disadvantage of the reversed nozzle arrangement, however, is that the type of nozzle generally used offers an obstruction to the air stream and tends to create excessive turbulence; the Summerland studies have indicated that a turbulent air stream has less penetrating power than a linear-flow air stream. A second consideration is that, by directing the liquid stream against the air stream, the energy inherent in the rapidly moving liquid is absorbed by that of the air stream instead of added to it. Although that may seem a minor matter there is measurable kinetic energy in a liquid emitted at two to three gallons per minute under a pressure of 300 pounds per square inch, and the fact is that most light, concentrate sprayers require all the air-liquid energy their engines, blowers, and pumps are capable of delivering. A third consideration in using reversed nozzles is that, with narrow, rectangular air vents, it is difficult to contain the spray cone within the air stream. In the work at Summerland a considerable number of pumps of various types have been examined by Mr. A. D. McMechan. He is of the opinion that a suitable method of using a low liquid pressure will eventually be developed for the rugged and simply designed concentrate sprayers that are favored by British Columbia fruit growers.

High-pressure pumps have several shortcomings. They are expensive, and most of them are fairly heavy and bulky. Spray concentrates containing wettable powders may be very abrasive when ejected under high pressure; consequently, high-pressure pumps necessitate the use of tungsten carbide parts at points of greatest wear, e.g., nozzle discs and swirl plates. On the other hand, the use of high pressure is, perhaps, the simplest method of reducing the size of spray droplets to the degree that appears to be necessary in concentrate spraying. Davies and Smythe-Homewood (17) listed pressure as the first factor influencing the degree of atomization. French (19) noted that, to reduce the size of spray droplets by one half, the pressure had to be increased four times. At a pressure of 300 pounds per square inch he recorded an average droplet diameter of 350 microns; at 500 pounds the droplet diameter was 250 microns. He concluded: "Pressure is the primary factor controlling the degree of atomization". A few years later Akesson (1) stated that the average droplet 
diameter of the spray from a high-pressure spray gun was 400 microns at 400 pounds' pressure per square inch, and 200 microns at 800 pounds per square inch: in other words, doubling the pressure halved the droplet size.

Early experiments on the control of orchard mites with the Bean MistDuster ${ }^{13}$ in British Columbia showed that neither perforated-tube manifolds, nor conventional nozzles operated at low pressure, were adequate for concentrate spraying. The machine, as received, was equipped with a rotary pump that developed a pressure of 20 pounds per square inch; the liquid manifold was a simple perforated brass tube inserted across the mouth of the air vent, in which position it caused pronounced turbulence in the air stream. 'The droplet spectrum, even at an air velocity of 120 miles per hour, was very wide, much of the liquid being projected as droplets over 400 microns in diameter. The perforated tube was replaced by a swirl-nozzle manifold attached to the outer edge of the blower scroll, in order to avoid unnnecessary air turbulence. The new manfold was so inclined that its 6 nozzles directed the spray forward into the air stream at an angle of 45 degrees. Although the droplets became smaller and more nearly uniform in size, atomization was still unsatisfactory for concentrate spray coverage; the dinitro phenol derivative that was being used as an acaricide caused foliage injury in the lower parts of the trees. When the rotary pump was replaced by a piston pump operated at a pressure of 300 pounds per square inch, atomization was further improved, spray injury was almost eliminated, and the control of mites was satisfactory throughout the trees.

Experiments with the Buffalo Turbine sprayer-duster ${ }^{14}$ in 1946 and 1947 confirmed these results. The low-pressure gear pump, and the perforated-tube manifold with which the machine was fitted, proved unsuitable for applying spray concentrates.

\section{Type of Nozzle}

Failure of the perforated-tube manifold emphasized the need for more information on the atomization of spray liquids. Writing of their pioneer work in Great Britain 22 years ago, Davies and Smythe-Homewood (17) said about swirl nozzles: "One popular misconception to be dispelled by these researches was that smaller disc orifices produce finer sprays. They do not." They found that the factors that do influence the degree of atomization are pressure, depth of swirl chamber, and size of vortex holes in the swirl plate. A decrease in the depth of the swirl chamber, or in the diameter of the vortex holes, produced smaller droplets and decreased the output of the nozzle; an increase in pressure produced smaller droplets but increased the output. Taylor (62) of New Zealand elaborated on the earlier work. He found that, at relatively low pressures, as the diameter of the disc orifices was increased the average diameter of the spray droplets increased; at high pressures, however, there was no change. According to Akesson (1), at orifice diameters above 0.05 inch the droplet sizes remain fairly constant, but below 0.05 inch the size of the droplets apparently becomes an increasing function of the orifice size; smaller orifices produce smaller droplets. Perhaps that is the reason for subsequent contradictory statements on the relationship between orifice diameter and droplet size. Taylor (62) noted that thicker swirl plates produced narrower spray cones and larger droplets, that an increase in the angle of the vortex openings produced slightly smaller droplets, and, the output being the same, four vortex openings appeared preferable to two, at least from the standpoint of droplet size.

${ }^{13}$ Food Machinery Corporation, Bean Division, San Jose, California, U.S.A.

14Buffalo Turbine Agricultural Equipment Company, Gowanda, New York, U.S.A. 
The two types of orchard concentrate sprayers manufactured in British Columbia depend upon high liquid pressure (300 to 400 pounds per square inch) and swirl nozzles to obtain the degree of atomization necessary in applying, from fixed air vents, as little as 50 gallons of spray concentrate per acre. One of the machines generates a linear-flow air stream with a velocity of about 110 miles per hour; the other, with considerably greater air volume but more turbulence, has an air velocity of about 90 miles per hour. The Summerland investigations have shown no appreciable reduction in the size of the spray droplets by either type of air stream.

Since it has been found that liquid spray formulations containing organic solvents are generally more prone to injure fruit or foliage than wettable powders, most of the orchard spraying in British Columbia is with the latter. But wettable powders applied at high pressure, and in high concentration, may be exceedingly abrasive. In the early days of concentrate spraying, faulty application was commonly traced to worn orifice discs or swirl plates and, less frequently, to worn pressure regulators or relief valves. Marshall (37) made a laboratory study of substances that might be used in the fabrication of orifice discs; he examined ceramics, natural rubber, plastics, various types of steel, and tungsten carbide, but only the last gave adequate resistance to abrasion. In commercial operations he compared stainless steel orifice discs, at that time in fairly general use, with tungsten carbide discs. The stainless steel discs were commonly ruined within 10 hours but, just as commonly, the tungsten carbide discs were still serviceable at the end of the season. Nowadays the nozzles of all concentrate sprayers manufactured in British Columbia are factory-equipped with tungsten carbide orifice discs and swirl plates. Australian and New Zealand manufacturers evidently follow the same practice.

With the swirl nozzle, according to Byass (6), 50 gallons per acre is the lowest volume of liquid that is feasible for mature orchards. He describes two compressed-air nozzles that, he claims, are capable of applying quantities as low as five gallons per acre. The more promising of the two nozzles consists of a number of tubes projecting at right angles into a circular opening through which compressed air passes at high velocity. Spray liquid, presumably moving at little pressure through the tubes, is atomized by the air stream. Compressed-air nozzles have not yet been examined at Summerland.

When it became evident that concentrate spraying was more than just a passing fad, several manufacturers hurriedly devised and marketed bizarre bits of equipment that they labelled concentrate sprayers. Evidently, in the interests of simplicity and low cost, some of these were equipped with the flat-jet, or fan, type of nozzle. Experiments at the Summerland laboratory and in the orchard have shown that fan nozzles do not atomize the spray liquid well enough to be satisfactory for concentrate spraying.

An efficient device for atomizing liquids is the whirling disc nozzle. Essentially it consists of a circular plate rotated at high speed. Spray liquid flowing onto this plate is thrown to the periphery in a fine sheet by centrifugal force. The sheet of liquid is fractured as it leaves the edge of the plate, and the fine droplets so produced are caught up and dissipated by the air stream of the sprayer. The whirling disc nozzle has two advantages over conventional nozzles: it is capable of producing unusually small and uniform spray droplets; and, since it operates at very low liquid pressure, it necessitates only a simple and inexpensive centrifugal pump. One disadvantage of the whirling disc nozzle is that, although simple in principle, it is not simple in construction; hence it is expensive and, it is suspected, somewhat liable to breakage or maladjustment. A second limitation is that, in all likelihood, the use of the whirling disc nozzle will be restricted to circular air vents, because, for efficient operation, it must be rotated by a high-velocity air stream. A modification 
of the whirling disc nozzle is fitted on a British-built concentrate sprayer recently examined at the Summerland laboratory. According to Mr. A. D. McMechan it produces droplets of more nearly uniform size and of lower mass median diameter, than most of the other nozzles so far examined.

A nozzle used to some extent in high-volume, air-blast spraying is the opposed-jet type. Two liquid jets from the orifices of this nozzle impinge on one another to produce a spray. At the Summerland laboratory, experimental work with the most widely used make of opposed-jet nozzle indicated that it was not adapted for concentrate spraying; apart from its high cost, which would be even higher if the nozzle were fitted with tungsten carbide orifice tips, it did not atomize the spray liquid sufficiently and its output was too great.

Another spray nozzle now being studied by Mr. A. D. McMechan at Summerland is the so-called anvil type, a device that reduces a jet of liquid to droplets by impingement on the end of a wirelike "anvil". This nozzle has the considerable advantage of simplicity, always a desirable feature in agricultural machinery; but it does not appear to provide sufficiently fine atomization for concentrate spraying, and the position of the anvil, or pin, is so critical that there is likelihood of misalignment.

In other fruit growing areas, special nozzles have been advocated, or are in use, for applying spray concentrates. Among the first investigators to study nozzles for the application of spray concentrates were Brann et al. (8), who developed a streamlined nozzle through which spray liquid was forced at a pressure of 100 pounds per square inch directly against the air blast. The nozzle, placed in the center of a circular air vent, was capable of applying spray liquid at various rates without the need of changing either nozzle orifice or pressure; the rate of application was varied by the adjustment of a flow valve. This type of nozzle, the use of which appears to be limited to circular air vents, has been fitted by manufacturers of concentrate sprayers in the United States and, apparently, in England. A Danish manufacturer has devised a nozzle that may be directed either with the air stream or against it. As with the other machines that depend, to some degree, on the atomizing effect of high velocity air stream, the blower scroll of the Danish one is formed of several circular vents.

\section{Angle of Emission of Spray Liquid}

Like high-volume, air-blast sprayers, some concentrate machines deliver the spray stream at a zero angle to the air stream. If, on such machines, the air vents are circular, a nozzle may be placed in the center of each; if rectangular, several nozzles are placed along the mid-line. The chief advantage of this arrangement seems to be that it streamlines the machine. Another benefit might be that it fully utilizes the kinetic energy of the spray droplets. No work has yet been done, however, to determine the significance of kinetic energy at outputs of less than 100 gallons per acre. A disadvantage is that, unless specifically designed to function in an air stream, the nozzles obstruct it and induce turbulence. Air velocity measurements show that the air speed for some distance outwards from an ordinary swirl nozzle is reduced almost to zero. If the blower develops a turbulent, high-volume air stream, the added turbulence induced by interposed spray nozzles is presumably of little consequence. In a low-volume, high-velocity, linear-flow air stream, however, nozzle-induced turbulence may lower the efficiency of the machine.

Other orchard concentrate sprayers deliver the spray stream at an angle of 180 degrees to the air stream, i.e., directly against it. The advantage of this method is that the greatest possible friction is generated between liquid and 
air, and the size of the spray droplets is reduced to a minimum. With a highvelocity air stream, the use of the inverted nozzle makes it feasible to employ a low liquid pressure, and hence a small, inexpensive pump. A disadvantage of this type of nozzle is that its use appears to be restricted to circular air vents. Rectangular air vents are generally so narrow that inverted nozzles tend to drive some of the spray droplets to the sides of the blower scroll. The resultant sheet of liquid is reconstituted by the air stream into droplets at the edge of the blower scroll but these are too large to be very effective in concentrate spraying. Circular vents can be used to advantage when they are manually directed; but, when mounted one above the other to form a fixed, multi-vent blower scroll for one-man operation, there may be complications. Unpublished records of Mr. A. D. McMechan of the Summerland laboratory showed that each of the four circular air streams from such a blower scroll maintained its identity, although to a decreasing degree, for a distance of 20 feet. Four distinct air streams are less likely to apply a uniform spray coverage than the single air stream emitted from a well-designed, rectangular air vent.

A third method of injecting the spray droplets into the air stream is a compromise between the other two. The spray liquid manifold is attached to the outer side of the blower scroll, and the nozzles are so inclined as to direct the atomized liquid at an angle of approximately 45 degrees into the air stream. This arrangement has the advantage of offering no obstruction to the air stream and, since the spray droplets are projected at a forward angle, their momentum may be somewhat greater than if they were projected directly against the air stream. On the other hand, the Summerland investigations indicate that the injection of spray liquid at a 45-degree angle into air streams moving at 90 to 115 miles per hour, such as are in general use in British Columbia, results in little if any reduction in the size of the droplets. The ultimate size of the droplets from the two British Columbia-built orchard concentrate sprayers is determined, therefore, by the type and pressure of the spray liquid and the type and arrangement of the spray nozzles.

\section{Rate of Travel}

Much of the uncertainty about concentrate spraying in some of the deciduous fruit industries of North America is undoubtedly due to lack of information on rate of travel. There have been many occasions on which light, concentrate sprayers, with very modest output of air, have been hauled twice to three times as rapidly as the manufacturer intended, and the unsatisfactory results blamed on the machine or the method. On the other hand, in the race for sales, manufacturers or their agents have sometimes oversold their machines, and extravagant claims for performance have not been substantiated in the orchard.

Although rate of travel is a matter of great importance, it is remarkable, to judge from the literature, how little attention has been paid to it. Using a high-velocity, concentrate sprayer, Brann (10) obtained better codling moth control when the machine was moved at 1.5 miles per hour than at 2 miles per hour. Pearch (50) warned that, in mist-spraying large trees in England, the rate of travel should not exceed 1.5 miles per hour. Akesson (1), whose views are typical of many operators of heavy equipment, has written: "In order to obtain the full benefits of blower sprayer operation it is necessary that the quantity of discharged air be sufficient to displace the air volume of the row of trees being passed." Brann (9) disagrees: "Some authorities have said that the air blast must have sufficient volume to displace the air in the tree.... If the equipment is moved at two miles per hour the air that must be displaced would be several times in excess of the air volume delivered by any machine now available". 
When hauled at a rate of one mile per hour, one type of British Columbia concentrate sprayer with a high-velocity, linear-flow air stream of only 7,000 cubic feet per minute gives satisfactory coverage of well-pruned, full-foliaged apple trees up to 30 feet in diameter and 18 feet high. If, to do so, it were necessary to displace all the air within such trees, the machine would have to be moved past them at a speed of approximately 0.2 mile per hour. Apparently, then, it is unnecessary to displace all the air within a tree when applying concentrate sprays with an air blast just as it is unnecessary to do so when applying high-volume spray liquids with a hand gun. The air within the tree, presumably, becomes mixed with that projected from the blower, and the mixture, highly turbulent by reason of the interference of branches, carries the spray droplets throughout the tree. It seems advisable, however, to travel slowly enough for the air stream to set the air in motion to the far side of the tree.

Various experiments have been carried out at the Summerland laboratory on this aspect of concentrate spraying. In 1949, for example, a light, one-side, air-blast sprayer, powered by a 5-horsepower engine and generating an air stream of approximately 5500 cubic feet per minute at an average velocity of 60 miles per hour, was operated experimentally in the control of the European red mite, Metatetranychus ulmi (Koch). It was hauled at one mile and two miles per hour among full-foliaged, 12-year-old apple trees approximately 20 feet in diameter and 15 feet high. Concentration of the acaricide, the monoethanolamine salt of dinitrocyclohexyl phenol, was the same at both speeds. A week after spraying the average percentage survival of mites in five separate trials was 27.7 where sprayed at two miles per hour, and 9.5 at one mile per hour. In every case survival was greater at the higher speed. With the reduced dosage of toxicant, clearly the machine in question was inadequate for spraying even rather small apple trees in full foliage, when operated at a speed of two miles per hour. On the other hand, at the same per-acre dosage of toxicant, the mites were satisfactorily controlled by a 25-horsepower turbine-type machine, travelling at two miles per hour and projecting approximately 7,000 cubic feet of air per minute at a velocity of 110 miles per hour.

In an experiment by Messrs. J. M. McArthur and A. D. McMechan (unpublished records), well-pruned apple trees approximately 27 feet in diameter and 18 feet high were sprayed at the pink-bud stage with methoxychlor, and the foliage was sampled for chemical analysis as soon as it had dried. The sprays were applied with the turbine, concentrate sprayer referred to in the preceding paragraph. In this instance both the speed and the concentration of toxicant were varied so that the same amount of methoxychlor was applied per acre, i.e., 12 pounds of 50 per cent wettable powder. The deposit in the tops of the trees was 250 micrograms per leaf at a rate of travel of one mile per hour (90 gallons per acre), and 278 micrograms at two miles per hour ( 45 gallons per acre, double concentration). In the bottoms of the trees the deposits were 233 and 281 micrograms respectively. It could not be said, therefore, that the higher rate of travel resulted in lower spray deposits in any part of the tree.

In another experiment with the turbine sprayer a lime-sulphur-dormant oil mixture was applied to mature apple trees as a dormant spray at rates of travel of one and two miles per hour, the per-acre dosages of oil and linesulphur being the same for each speed. Deposits of oil on twigs in the tree tops averaged 0.46 milligram per square centimeter at two miles per hour, and 0.51 milligram per square centimeter at one mile per hour. In the bottoms of the trees the respective figures were 0.41 and 0.42 milligram. Control of the European red mite was approximately the same in each instance. A pink-bud 
spray of an Ovotran-methoxychlor mixture was applied at the two speeds to other plots in the same orchard. Both the deposit of spray chemical and the control of mites were similar to those in the preceding experiment.

Evidently the 25-horsepower, one-side, concentrate sprayer now being manufactured in British Columbia may be operated throughout the spraying season at a speed of two miles per hour among apple trees up to about 20 feet in diameter and 15 feet high. In large, well-pruned trees, 30 feet in diameter and 18 to 20 feet high, a speed of two miles per hour seems adequate from dormant to pink-bud stage; for such trees in full foliage more information is needed, and experiments to that end are now under way. In the meantime, the official recommendation for British Columbia fruit growers (2) is to operate concentrate sprayers at a speed of one mile per hour in mature plantings with rows 30 feet apart, at $1 \frac{1}{2}$ miles per hour in mature plantings with rows 20 feet apart, and at two miles per hour in plantings with rows 15 feet apart. The growers have been notified, however, that it is feasible to increase the speed measurably, up to the pink period of apple bud development, provided they operate efficient, adequately powered concentrate sprayers.

\section{SPRAY COVERAGE}

Twenty-three years ago the British investigators Davies and SmytheHomewood (17) noted that biologists did not agree on the ideal type of spray coverage. The plant pathologists favored a fine, mistlike coverage, whereas the entomologists preferred a driving type of spray, even to the point of dripping. But they added: "It appears that all would be satisfied if every part of the sprayed objects were evenly covered with a finely divided, stippled deposit". Beskine (5) mentioned that, although 150-micron droplets are efficient enough for controlling insects, they are too large for fungi. In spraying with mist concentrates, Brann (9) claimed the ideal cover is not a continuous film, nor the blotchy type of deposit normally laid down by a high-volume sprayer, but a finely spotted deposit. Wittwer and Muller (65) found that the greatest resistance to weathering was from droplets 30 to 50 microns in diameter. Goossen (24) stressed the need for an unbroken filmlike coverage of fungicide to control plant diseases, and emphasized that coverage of the kind is more readily attained with high-volume than with concentrate spraying.

Early in the commercial use of concentrate sprayers in British Columbia it was observed that the growers were having more trouble in controlling apple scab than the codling moth or phytophagous mites; yet the opposite had been the case in the days of high-volume spraying. It was suspected that the trouble lay in the tendency of even the most efficient concentrate sprayers to overspray surfaces facing the air stream, and to underspray surfaces not facing the air stream, such as the stem-basins of well developed fruit, i.e., there is a tendency to produce a "shadow" effect. Theoretically, a uniform, filmlike deposit should be more important in dealing with a motionless organism such as an apple scab spore than an active insect or mite. In the first instance, the toxicant must be placed close to or in contact with the spore, a requirement that can be met readily by the washing effect of high-volume spraying; in the second, the object of the spray unwittingly seeks out the toxicant, so that the deposition of the toxicant, even though relatively irregular, may be adequate for the job.

A Netherlands manufacturer has developed a machine that is said to be capable of producing droplets with an average diameter of approximately 50 microns. Droplets of that size, it is claimed (undated brochure of Kiekens Whirlwind (London) Ltd.), are caught up in air eddies behind leaves and 
fruit, and eventually come to rest in sufficient quantity to give protection even on surfaces facing directly away from the sprayer. So far, the Summerland investigations have not shown how that can be accomplished, although they have included experiments with steam-atomized and with hydraulically atomized spray liquids, the average droplet sizes of which lay between 30 and 100 microns. Whether these droplets were projected in a turbulent air stream or in a linear-flow air stream, only a very small percentage were deposited on surfaces facing away from the machine.

Despite the fact that spray coverage on reverse surfaces was deficient, however, chemical analyses repeatedly showed that concentrate spraying resulted in higher spray deposition on the tree than high-volume spraying with an equal quantity of toxicant. Obviously there was much room for improvement in the uniformity and completeness of the spray coverage. Since it appeared unlikely that the necessary improvement could be accomplished by mechanical means, an investigation was begun to determine whether it could be done chemically. Five years later the use of surface-active chemicals to enhance the performance of concentrate spray mixtures became commercial practice in British Columbia. Despite this development, however, the use of such preparations in concentrate spraying is still a controversial subject. Some investigators consider that the idea has possibilities; others say it is out of the question because it will lead to excessive spray injury. The matter is important enough to merit considerable discussion.

\section{SURFACE-ACTIVE ADJUVANTS（SURFACTANTS）}

\section{Physical Characteristics of Spray Liquid}

Recently Brann (11) commented: “... we can not go on solving problems by building larger machines with more air blast. Progress lies in the direction of more efficient application of the power we are now using through a better understanding of the factors involved in getting the toxicant from the tank to the plant". Among the most important of those factors are certain physical characteristics of the spray liquid-homogeneity, volatility, viscosity, density, and surface activity.

\section{Homogeneity}

In concentrate spraying it is important that the composition of the spray liquid be constant from start to finish of the operation. Unlike high-volume spraving, in which a variation of as much as 100 per cent in the concentration of an ingredient probably might go unnoticed, any such variation in concentrate spraying may have profound effects. Agitation of the concentrate spray liquid, therefore, requires special consideration. Some manufacturers have fitted their sprayers with tanks of rectangular, or approximately rectangular, cross section. If the agitation is vigorous such tanks are satisfactory, but if for any reason it should weaken, settling is likely to occur in the corners; consequently, round or oval tanks are preferable.

The Summerland investigations have indicated that mechanical agitation is preferable to hydraulic agitation. Mechanical agitation is the more reliable method and has the added advantage that it does not necessitate a high-capacity pump. Agitation should not be so great that air may be carried into the suction line to cause air locks in the pump. For mechanical agitation, flat paddles or propeller-type paddles are generally used, the former, as a rule, being somewhat more effective. 


\section{Volatility}

The application of ultra low-volume sprays ( 3 to 20 gallons per acre) necessitates exceptionally fine atomization. It appears, from several published articles, that there is no trouble from evaporation of such spray droplets in districts with relatively high atmospheric humidity and moderate temperatures. But in semi-arid areas, such as the Okanagan Valley of British Columbia, indications have been that spraying at the rate of 20 gallons per acre may, to a degree, become dusting. It is to be expected that, in rapidly moving air at a temperature of $100^{\circ} \mathrm{F}$. or higher and a relative humidity of perhaps 15 or 20 per cent, minute droplets of water will be in a highly unstable condition. Zimmer (69) remarks that "even in a temperate climate all small volume sprays are susceptible to loss by evaporation. It is often necessary to minimize this by preparing the solution in an oil of suitably high boiling point".

There has been a marked disinclination to use petroleum oils as foliage sprays in British Columbia. The general adoption of concentrate spraying has emphasized the hazards of the commonly used petroleum fractions, and it is doubtful whether with the present machinery, even the phytonomic summer oils will be employed. In any case, a dosage of 50 gallons per acre, as now suggested, appears to be high enough to ensure that an adjuvant will not be needed to minimize the effects of evaporation, yet low enough to give a substantial saving through protracted operation between fillings. Investigations now in progress indicate that a dosage of as little as 35 gallons per acre may be feasible in British Columbia; but dosages of that order must be applied with special care and with the best of equipment. Present indications are that such low dosages may necessitate the use of a surfactant in the spray concentrate. The point is discussed later.

\section{Viscosity and Density}

In calculating the size of spray droplets, Nukiyama and Tanasawa (46) developed a formula in which the flow of liquid, the flow of air, the velocity of gas and liquid relative to one another, the viscosity of the liquid, the density of the liquid, and the surface tension of the liquid are variables. In the application of oil sprays Potts and Friend (53) found that an increase in the viscosity of oil from 50 to 200 seconds, as measured by the Saybolt Universal viscosimeter at $100^{\circ} \mathrm{F}$., resulted in an increase of nearly 100 per cent in the size of the spray droplets. At Summerland a similar effect was observed in experiments in which, as the viscosity of a DDT wettable powder spray concentrate was raised by addition of carboxymethyl cellulose, the size of the spray droplets increased and the spray coverage became irregular and spotty.

Although spray concentrates may contain more than a pound of finely divided, suspended material per gallon, it is doubtful whether their viscosity varies appreciably from that of water alone. On the other hand, their density is generally greater than that of water; and as Nukiyama and Tanasawa have pointed out, the greater the density of the spray liquid the larger the spray droplets. It has to be remembered, though, that a spray concentrate may not be a pure liquid, or even a solution, but a two- or three-phase system, so that its behavior cannot be deduced by analogy from that of pure liquids of similar density.

In any case, density appears to be a more important factor in concentrate spraying than viscosity. It is also a more important factor in concentrate spraying than in high-volume spraying. Any measures that might be taken to offset the influence of high density, therefore, should be given due consideration. One such measure is the modification of the surface tension of the spray liquid, or the interfacial tension between the spray liquid and the sprayed surface, by the addition of an appropriate surface-active preparation. 
Surface Activity

Among the first to examine the effects of surface-active materials in spray concentrates were Potts (52), who stated that the droplet size in a concentrate spray may be reduced 30 to 50 per cent by the addition of a good wetting agent, and Pratt (55), who mentioned having used the non-ionic, water-dispersible surfactant Triton B 1956 (Rohm and Haas Co., Philadelphia, U.S.A.) with water-wetted sulphur dust. The surfactant measurably increased the amount of sulphur residue on fruit and foliage.

As concentrate spraying became more widely studied, references to wetting agents and other surfactants became more frequent. Among those who considered that surfactant should not be added to spray concentrates were Besemer (4), Foulds et al., (20), Moore (45), Hey (30), and Young (67, 68). These authors agreed that the spray droplets should not be allowed to spread to the point of coalescence. Their disapproval of surfactants varied from the opinion expressed by Young (67), "In the case of concentrate sprays, the low gallonages and high concentrations of materials makes complete wetting of the surfaces impossible. For this reason the matter of uniform distribution is more strictly a function of the spray machine" to the categorical advice of Hey, "Do not use wetting agents with low-volume sprays...".

Among those who mention that surfactants might prove useful is Brann (9), who, although stating that the ideal deposit in concentrate spraying is not a continuous film, but a finely spotted deposit, nevertheless suggests the use of a spreader such as vegetable oil or the non-ionic surfactant Triton B 1956 at the rate of four to six ounces per 100 U.S. gallons of spray liquid, particularly if wettable powders are to be applied. In true concentrate spraying, as defined earlier (not over 75 imperial gallons per acre of mature trees), such an amount of either of these preparations is too small to produce a film coverage.

Noting that the penetration of spray through thick foliage is best accomplished by small droplets, Edwards and Ripper (18) proposed the use of wetting agents and high pressures to improve the atomization of the spray liquid in herbicidal applications; but there is difference of opinion as to whether wetting agents have any such effect. Parker (48) was one of the first workers to emphasize that surfactants may be necessary if the potential effectiveness of concentrate spraying is to be fully realized. In 1950 he wrote: "Spreaders in the water seem to be important if this small amount of liquid is to provide adequate coverage". He considered that the most pressing research problems in concentrate spraying related to spray formulations. The following year Hamilton (27) stated that, since high concentrations of solids produced concentrates that are difficult to "break up", a surfactant such as the water-soluble, non-ionic Triton X100 (Rohm and Haas Co., Philadelphia, U.S.A.) may be added to good effect at a concentration of one pint per 100 gallons of spray concentrate.

The relationship between surface tension and size of droplet has been mentioned by Potts and Friend (53) who stated that the addition of the surfactant Santomerse D (Monsanto Chemical Co., St. Louis, U.S.A.), at two per cent by weight of the suspended solid, reduced the droplet size of a lead arsenate spray concentrate by 20 per cent. Writing on the manner in which liquids are reduced to droplets, Zimmer (69) claims, however, that a swirl nozzle forces the liquid into a thin sheet which, as the result of air friction, breaks up into rodlike ligaments. The ligaments in turn break up along their length into troplets in a manner controlled mainly by the surface tension of the liquid. He suggested that a surfactant could not influence the process because there would be insufficient time for the surfactant to reach the new surfaces before the process was completed. 
As mentioned earlier, Mr. D. B. Waddell of the Summerland laboratory found that the turbine type of concentrate sprayer, widely used in British Columbia, produced a droplet spectrum in which only about two per cent of the droplets were above the maximum wanted diameter of 100 microns. Those few large droplets, however, represented about half of the volume of the spray liquid. Various authors have stressed that, since spray concentrates are applied in relatively small amounts, the droplets must be very fine, and closely and uniformly spaced. That being so, the detrimental effect to the spray coverage of the two per cent of large droplets must be considerable. But if, by modifying the surface activity of the spray liquid, all the droplets coalesced after impact to form a liquid film, then, provided the large droplets did not fall away from the air stream too rapidly, and provided they were able to penetrate the foliage canopy, the volume of spray material represented by the large droplets might be as effective in protecting the foliage and fruit as an equal volume in the form of small droplets.

\section{Experiments with Surfactants}

There are two reasons for caution in using a surfactant to improve the efficiency of concentrate spray coverage. First, the addition of a surfactant, in sufficient amount to produce a uniform liquid film on fruit or foliage, may result in the formation of a heavy, objectionable residue at points from which there is drip. Second, if a spray chemical has a tendency to be phytotoxic, the tendency is aggravated by the formation of localized, heavy deposits.

The first of these difficulties can be avoided by attention to type of machine, and method of operating it, and to dosage of spray concentrate. The machine should apply the spray liquid in such a manner as to avoid unnecessary overspraying of the lower parts of the trees. The quantity of spray liquid should not exceed 75 gallons per acre of mature trees; as shown later, 50 gallons per acre appears to be sufficient, particularly if a surfactant is used in the spray concentrate. The same precautions will minimize the second difficulty; avoidance of spray chemicals that are prone to cause injury will, of course, eliminate it.

In British Columbia the first field experiments with surfactants in concentrate spraying were undertaken in 1952 against the codling moth. But neither in that year nor in succeeding years, including 1956, were weather conditions favorable enough for the insect to develop the heavy infestations that are desirable in field experimentation. Nevertheless, repeated trials indicated that control of the codling moth was improved when a surfactant was added to the spray mixture. For example, 50 per cent DDT wettable powder was applied at six pounds per acre, in five separate, large-scale experiments, in plots of one-quarter to one-half acre. In each instance, codling moth infestation at harvest was lower where a surfactant had been added to the DDT concentrate. Where no surfactant had been used, the average infestation was 4.0 per cent; with surfactant it was 2.2 per cent. With three pounds of 50 per cent DDT per acre the average infestation was 12.0 per cent without surfactant and 7.9 per cent with surfactant; again the differences in separate experiments were in favor of the surfactant mixture.

In recent years control of apple scab has been a serious problem for many British Columbia fruit growers. It has been mentioned earlier that, although concentrate spraying generally results in deposits of fungicides that are adequate from the standpoint of chemical analysis, the deposits are not entirely adequate from the standpoint of scab control. The difficulty, it was suspected, arises from the irregularity of the spray coverage. Since it was known from 
codling moth experimentation that certain surfactants have the capacity to eliminate "shadow effect", and produce a barely visible, film-type coverage without loss of toxicant, it seemed reasonable to assume that, if inferior scab control did indeed result from unprotected areas on the surface of fruit or foliage, the addition of an appropriate surfactant to the fungicidal spray mixture should render the mixtures more effective. As an outcome of duplicated orchard experiments to test that theory, Swales and Williams (61) reported that surfactants measurably improved the effectiveness of fungicidal spray concentrates. Without surfactant a spray schedule of lime-sulphur, ferbam, wettable sulphur (the fungicidal mixtures applied at 75 gallons per acre in seven applications) resulted in an average of 11.7 per cent scabby fruits at harvest. Plots sprayed with the same fungicides but with added surfactant yielded 4.1 per cent scabby fruits. Where a fungicide schedule of ferbam, wettable sulphur was followed throughout the season the respective figures were 13.5 per cent and 7.7 per cent; non-sprayed check trees were largely defoliated and the fruit was 100 per cent scabby. The differences were consistent in the two orchards.

The following year the same investigators (unpublished work) reproduced these results with a dosage of 75 gallons per acre, and showed that the dosage might be reduced to 50 gallons per acre if a surfactant was added to the spray mixture. In duplicate experiments, the idividual plots being about a third of an acre in area and the dosage 50 gallons per acre, they found the average scab infection at harvest to be: without surfactant, 54.4 per cent; with surfactant, 26.1 per cent. Again the fruit on the non-sprayed check trees was a total loss; again the differences were consistent in the two orchards. Scab infection on the sprayed plots was abnormally high because of exceptionally prolonged precipitation, which on one critical occasion seriously delayed the spray application.

Ranking with the codling moth and apple scab as bugbears of the orchards in British Columbia are several species of phytophagous mites. In field experiments against the European red mite, Metatetranychus ulmi (Koch), and the two-spotted mite, Tetranychus telarius (L.), acaricides applied with and without surfactant have shown no measurable differences in control. Presumably that is because with active organisms such as mites, a uniform spray coverage is not necessary; the mites come in contact with the toxicant during their wanderings whether it is deposited as a uniform film or as discrete spots. A second consideration is that certain acaricides may be lethal although not immediately in contact with the mites.

Aphids are also troublesome orchard pests in British Columbia; the apple aphid, Aphis pomi DeG., and the woolly apple aphid, Eriosoma lanigerum (Hausm.), are among the most prevalent and the most injurious. One of the standard procedures in controlling both species is to anply, during warm weather, a spray of nicotine sulphate at 0.5 gallon and sodium carbonate (washing soda) at two pounds per acre. In an experiment, undertaken to determine whether the addition of a surfactant affects the toxicity of the nicotine mixture, several acres of mature orchard heavily infested by the apple aphid were spraved with a standard mixture, and an equal area sprayed with the same mixture to which a surfactant had been added. From the commercial standpoint, control of the aphid was equally good with both spray mixtures.

A few years ago it was thought that the woolly apple aphid was so well protected by its waxy covering that only as a drenching spray could a toxicant be brought into effective contact with the insect. Experience has shown that, in warm or hot weather, the aphid is readily controlled by the application of as little as 50 gallons of nicotine spray concentrate per acre, an amount 
far short of that required to wet and penetrate the aphid wax in liquid form. The addition of a surfactant has been of no evident benefit. Presumably there is no point in adding a surfactant to concentrate spray mixtures of the fumigant type, such as the one in question.

In many fruit growing areas, one of the more bothersome problems in apple production nowadays is the control of apple powdery mildew. It has been claimed by several writers, Sprague (59), Hunnam et al. (32), and Hey (30), for example, that, even in high-volume spraying, the addition of a wetting agent measurably improves the control of the disease by sulphur sprays or Karathane (dinitrocapryl phenyl crotonate). It is logical to assume that the beneficial effects of a surfactant would be even more pronounced in concentrate spraying. Extensive field experiments were undertaken in 1956 and 1957 to determine whether that is so; but weather conditions reduced mildew infection to such a low point that the results were inconclusive, and the trials must be repeated.

Field experiments were undertaken to find out whether the addition of a surfactant affects the scale-killing properties of dormant oil-lime-sulphur spray concentrate. The oil, emulsified with soya flour, quickly separated from the water phase of the emulsion after the regularly recommended, waterdispersible, non-ionic surfactant, Triton B 1956, had been added to the spray mixture; it was therefore necessary to substitute the water-soluble, non-ionic preparation Triton X100 (Rohm and Haas Co., Philadelphia, U.S.A.). A month later trees sprayed with standard dormant oil-lime-sulphur mixture (dormant oil, 220 S.S.U. viscosity at $100^{\circ} \mathrm{F}$., six gallons per acre, plus lime-sulphur, $32^{\circ}$ Be., 12 gallons per acre) showed 99.4 per cent mortality of the San Jose scale, Aspidiotus perniciosus Comst.; trees sprayed with the same mixture plus 0.25 per cent of Triton X100 showed 99.8 per cent scale mortality; non-sprayed trees showed 65.7 per cent mortality. It is suspected that there is little if any advantage in adding a water-soluble surfactant to a spray mixture having the pronounced wetting capacity of petroleum oil-lime-sulphur. It is difficult to find heavy infestations of the San Jose scale in British Columbia, so that it has not been possible to repeat the experiment.

\section{Type and Quantity of Surfactant Necessary}

Experiments with such surface-active compounds as sodium lauryl sulphate, triethanolamine oleate, saponin, soap bark, and certain commercial wetting agents that are widely used in high-volume spraying showed that the requirements of concentrate spraying necessitated a new approach. Even in high concentration the commonly used, detergent-type of surfactant failed to produce a film coverage when added to a spray concentrate heavily charged with finely divided solids. The low concentrations of the surfactants (wetters and spreaders) common in high-volume spraying proved inadequate in concentrate spraying. Anionic and cationic surfactants were evidently too likely to prove incompatible with a number of the present-day pesticides. Water-soluble surfactants were considered unsatisfactory because of their lack of resistance to heavy rainfall. When present in relatively high concentration, and subjected to the strong agitation necessary for spray concentrates, many surfactants foam heavily, and cause air locks in high-pressure spray pumps; the result is a variable output of spray liquid.

Eventually it was determined that the desired coverage could be obtained by the use of the non-ionic, water-dispersible, low-foaming surfactants Triton B 1956 (Rohm and Haas Co., Philadelphia, U.S.A.) and Colloidal Spray Modifier (Colloidal Products Corp., San Francisco, U.S.A.). The latter was formulated particularly for use with spray concentrates. 
The impression of most writers who admit the possibility of using surfactants in concentrate spraying seems to be that the same concentration of surfactant is required as in high-volume spraying. Hunnam et al. (32), for example, found that certain surfactants improved the control of apple powdery mildew in high-volume spraying, and presumed they would do so in low-volume spraying if used at the same concentration. For high-volume spraying the surfactant Triton B 1956 is recommended by the manufacturers at one to two ounces per 100 gallons; but, in concentrate spraying at 50 gallons per acre, 40 ounces per 100 gallons has proved necessary to provide a satisfactory film coverage. Evidently, when spray droplets are very fine and the quantity of liquid is insufficient to induce marked coalescence of droplets, the quantity of surfactant necessary to produce a film coverage is much greater than would be expected from experience with high-volume spraying. The point has been mentioned by Srivastava and Srivastava (60), who determined that the concentration of soap required to produce complete wetting of foliage became greater as the spray droplets became smaller.

Lacking an adjuvant, a concentrate spray mixture applied at 75 gallons or less per acre of mature apple trees forms an obviously spotted deposit. When an appropriate surfactant is added, the spray liquid forms a film, and the resulting residue is barely visible (Fig. 8). According to Mr. K. Williams, (unpublished work) of the Summerland laboratory, repeated analyses reveal that the lack of deposit is merely apparent. In the application of DDT wettable powder, for example, the amount of spray residue on the lower parts of large trees, i.e., over 20 feet in diameter and over 15 feet high, or throughout small trees, was approximately the same whether a surfactant had been added to the spray mixture or not. In the tops of large trees, however, where adequate spray coverage is generally hardest to achieve, the addition of a surfactant consistently increased the amount of spray deposit; the increase has varied
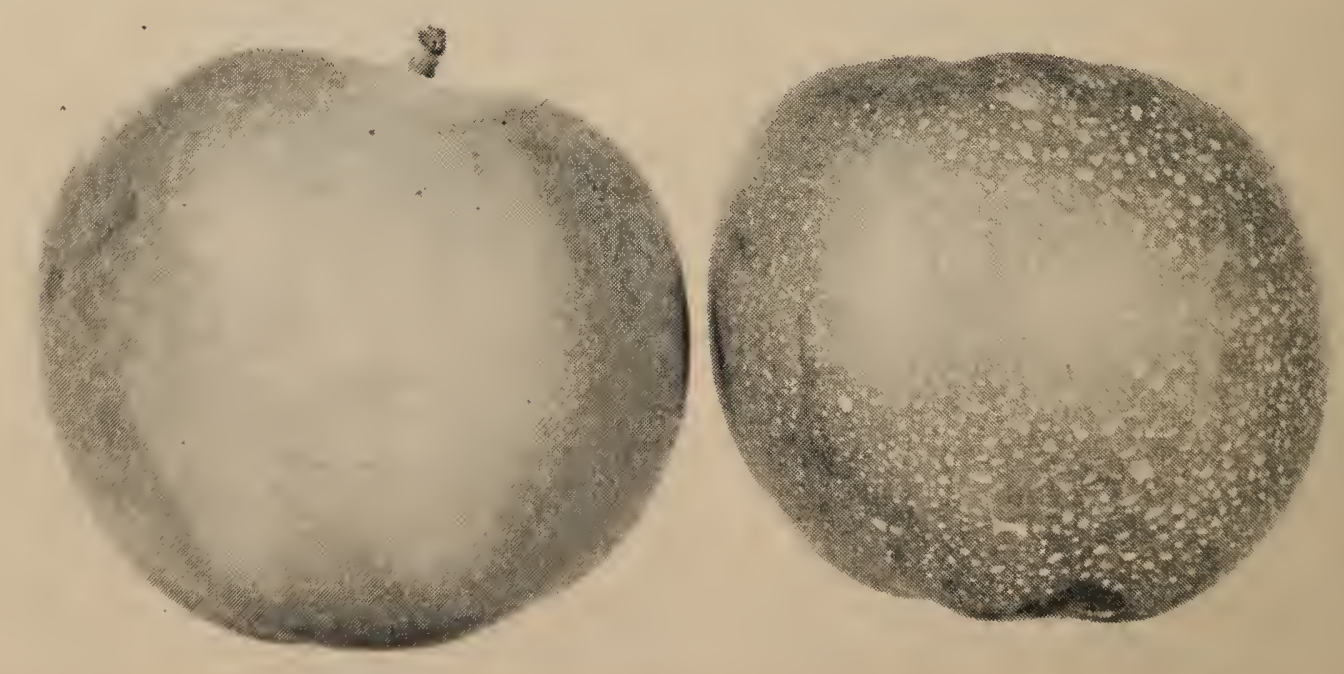

Figure 8-McIntosh apples sprayed with 50 per cent DDT wettable powder at six pounds in 65 gallons per acre. Left DDT-surfactant mixture; right, DDT alone.

from 20 per cent upwards. These analyses have special significance because one of the shortcomings of concentrate spraying is the tendency to overspray the lower parts of the trees. If a surfactant were to cause heavier spray deposition in the lower parts of the trees, as it does in the upper parts of large trees, that would be a serious handicap to its use. Perhaps the chief benefit 
from the use of surfactants in controlling the codling moth and apple scab has come from the improvement in the quality, or type, of the spray deposits. But it seems probable, too, that the greater deposit in the tops of large trees is important, because it is there that adequate coverage is most frequently lacking.

\section{Function of Surfactants}

The way in which a water-dispersible surfactant improves spray coverage is not yet well understood. Laboratory experiments by Mr. K. Williams, (unpublished work) of the Summerland laboratory, suggest that the presence of such a surfactant in a concentrate spray mixture increases the deposition of spray liquid on surfaces exposed to the spray blast at angles of 45 degrees or less. Possibly, when there is high interfacial tension between droplet and the sprayed surface, the droplet has a tendency to ricochet when it impinges on an inclined surface; that being the case, if the interfacial tension is reduced, as by the addition of an appropriate surfactant, the droplet should be more likely to adhere on impact and thus promote uniform spray coverage.

It has been observed that the surfactants now in commercial use in British Columbia appear to increase the density of a concentrate spray mist. Experiments with a commercial, turbine type of concentrate sprayer, on surfaces exposed at an angle of 90 degrees to the spray stream, showed that no more spray droplets were deposited from a Rhodamine B dye solution containing the surfactant Triton B 1956 than from a solution lacking the surfactant. Evidently the water-dispersible surfactant did not reduce the size of the spray droplets and thus increase their number and hence the density of the spray mist. Perhaps the apparent increase in the density of the spray mist is an optical effect arising from the opacity imparted to the spray liquid by the surfactant.

\section{CONTAMINATION OF SOIL BY SPRAY CHEMICALS}

In the spraying of orchards a problem not always given the consideration it merits is contamination of the soil by spray chemicals. The serious losses that occurred from the poisoning of orchard soils by lead arsenate in Colorado and Washington in the '30's and early '40's were a warning that greater care should be taken to minimize the amounts of persistent spray chemicals that might reach the soil. Several experiments carried out by Dr. J. M. McArthur and his associates (unpublished data) in the Okanagan Valley of British Columbia have shown that concentrate spraying has a practical bearing on the problem. In one case, for example, chemical analyses were made of the cover crop in a mature apple orchard, with trees 30 feet apart, that had been sprayed with 50 per cent wettable DDT powder, in part by high-volume spraying at 0.22 pound of wettable powder per tree and in part by concentrate spraying at 0.17 pound per tree. Since the trees nearly touched one another, approximately 80 per cent of the orchard floor was beneath them. The following figures represent, on a dry-weight basis, the parts per million of DDT on the cover crop:-less than five feet from the tree trunk: high-volume spraying, 2,790 ; concentrate spraying, 580; five to 15 feet from the trunk: high-volume, 2,360; concentrate, 620 ; between trees: high-volume, 970 ; concentrate, 645 . Over the two sprayed areas there was on the average about 2.5 times as much DDT on the cover crop for high-volume spraying as for concentrate spraying, although not quite one-third more DDT was applied by the high-volume procedure. Doubtless the chief reason for the difference in amounts of spray chemical reaching the cover crop, or orchard floor, is the absence of drip, or "run-off", from concentrate application. 
Because of data such as these, and extensive experiments to determine effective dosages, the recommended quantities of spray chemicals per acre are generally markedly lower in British Columbia than in areas where insect and disease control problems are similar but high-volume spraying is still the general practice. Just how great the differences may be is shown in Table I, which gives the quantities of some spray chemicals recommended per-acre for concentrate spraying in the official spray recommendations for 1956 for British Columbia (2) and for high-volume spraying in the neighboring State of Washington (3).

\section{TABLE I}

Recommended Amounts of Spray Chemicals per Acre for Concentrate Spraying in British Columbia and for High-Volume Spraying in Washington in 1956

\begin{tabular}{|c|c|c|c|}
\hline \multirow[b]{2}{*}{ Application } & \multirow[b]{2}{*}{ Chemical } & \multicolumn{2}{|c|}{ Amount per acre (pounds or imperial gallons) } \\
\hline & & $\begin{array}{l}\text { British Columbia } \\
\text { (Concentrate) }\end{array}$ & $\begin{array}{c}\text { Washington } \\
\text { (High-Volume) }\end{array}$ \\
\hline $\begin{array}{l}\text { Dormant..... } \\
\text { Dormant.... }\end{array}$ & $\begin{array}{l}\text { Lime-sulphur. . } \\
\left\{\begin{array}{l}\text { Lime-sulphur. . } \\
\text { Dormant oil... }\end{array}\right.\end{array}$ & $\begin{aligned} 20 & \text { gal. } \\
12 & \text { gal. } \\
6 & \text { gal. }\end{aligned}$ & $\begin{array}{r}73 \text { gal. ( } 88 \text { U.S.) } \\
19.9 \text { gal. (24 U.S.) } \\
9.9 \text { gal. (12 U.S.) }\end{array}$ \\
\hline $\begin{array}{l}\text { Pre-pink....... } \\
\text { Pink......... } \\
\text { Codling Moth. }\end{array}$ & $\begin{array}{l}\text { Lime-sulphur.... } \\
\text { Karathane...... } \\
\left\{\begin{array}{l}\text { DDT, } 50 \%, \text { plus } \\
\text { Parathion, } 15 \% .\end{array}\right.\end{array}$ & $\begin{array}{l}8 \text { gal. } \\
5 \mathrm{lb} \text {. } \\
6 \mathrm{lb} \text {. plus } 0.75 \text { qt. } \\
\text { surfactant } \\
\text { none }\end{array}$ & $\begin{array}{l}16.6 \text { gal. (20 U.S.) } \\
8 \mathrm{lb} . \\
16 \mathrm{lb} . \\
3 \text { to } 8 \mathrm{lb} .\end{array}$ \\
\hline
\end{tabular}

\section{PRESENT STATUS OF CONCENTRATE SPRAYING}

It is probably significant that concentrate spraying is most sharply criticized chiefly in the fruit growing areas where it has not been carefully investigated. On the other hand, even with the admittedly second-rate concentrate sprayers commonly in operation, apparently few orchardists have reverted from concentrate to high-volume spraying. The logic of the method cannot be denied; light, low-priced equipment, minimum soil compaction, minimum quantity of spray chemicals, minimum soil contamination, and minimum water requirements, are features that the commercial fruit grower cannot afford to overlook.

There have been, of course, frequent reports of poor pest or disease control from concentrate spraying. Generally the trouble seems to have arisen from faulty or underpowered equipment, or from failure to appreciate the importance of proper dilution, nozzle adjustment, rate of travel, or tree pruning. But "Too much spray injury" is the argument most often used against concentrate spraying. On several occasions that argument has been traced to misinformation as to what concentrate spraying actually is; on other occasions, to the exuberance of sprayer salesmen; and sometimes it seems merely to have been a matter of a common human tendency to resist change, or the urge to be considered a cautious adviser.

Frequently "semiconcentrate" spraying, with from 150 to 300 gallons of spray liquid per acre, is advanced as a means of reducing spray injury. Yet semiconcentrate spraying results in drip, and to judge from the Summerland 
investigations, only with highly dilute spray mixtures can drip be safely permitted. As concentrate spraying becomes better understood and poor machines are eliminated, it seems probable that semiconcentrate spraying will be given up. Because there are, in British Columbia, a number of so-called concentrate sprayers incapable of applying strictly concentrate sprays, semiconcentrate spraying is still practised in this province; but concentrate spraying is now the generally accepted method. Uncertainties as to effectiveness, spray injury, and quantities of spray chemicals per acre have been largely cleared up, although there is still some difference of opinion as to optimum amount of spray liquid per acre. As inefficient machines become fewer, about 50 gallons per acre of mature trees may become standard dosage (Fig. 9). Rate of travel may vary somewhat, according to capacity of machines and according to season, i.e., up to and including the pink-bud spray, the machines may travel about twice as fast as for full-foliage sprays.

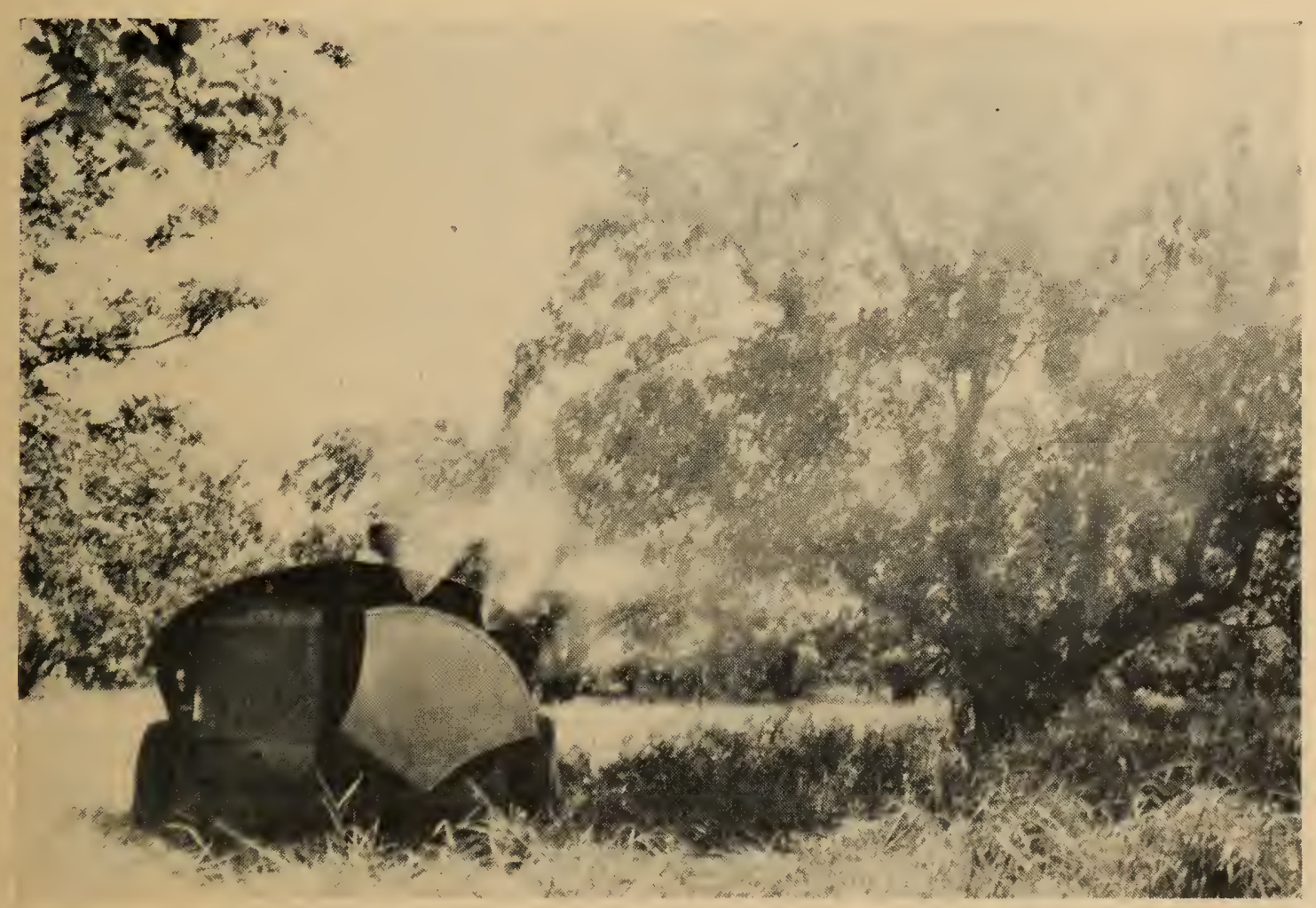

Figure 9-One-side concentrate sprayer applying 50 gallons of spray concentrate per acre. The spray mist can only be seen clearly when viewed against the sun.

Indications are that the deciduous fruit industries of Australia and New Zealand will be the next to adopt concentrate spraying as standard procedure. Already several hundred concentrate machines are operating in the Antipodes. In Great Britain, Holland, and Denmark there appears to be increasing interest in concentrate spraying, and several types of low-volume sprayers, as they are commonly known overseas, are available. Sharp differences of opinion as to dosages per acre appear to have led to some uncertainty about low-volume spraying among fruit growers in Great Britain; but, whether the 50 -gallon dosage or the ultra low-volume three to 10 gallon dosage will eventually prevail, there is reason to believe the new practice will steadily become more popular.

The degree of acceptance of concentrate spraying in North America appears to parallel its study. In New York State and New England, where most of the recent United States research on orchard spray applicators has been done, 
concentrate spraying is widely practised. But in the huge orchard areas of the Pacific States, where there has been little research on the method, relatively few fruit growers use it. In Canada the situation is reversed. Most of the research has been done in the west, and most of the concentrate machines are in the west. For the last several years the investigations at the Science Service Laboratory, Kentville, Nova Scotia, have been giving reliable guidance in concentrate spraying to the fruit growers of that province, and now, it is understood, a turbine type of concentrate sprayer is to be built and marketed there. The general mechanization of spraying by means of concentrate equipment may be fairly close at hand in Nova Scotia and New Brunswick.

According to Mr. G. G. Dustan, Officer in Charge, Entomology Laboratory, Vineland Station, Ontario, and Mr. A. A. Beaulieu, Officer in Charge, Science Service Laboratory, St. Jean, Quebec, most apple growers in Ontario and Quebec now use automatic sprayers of one kind or another. Machines without fans are of the high-volume type; those with fans may be either high- or lowvolume. Fan-equipped machines have proved more efficient than those without fans. Many growers now use low-volume, air-blast machines, but because of their large orchards and densely foliated trees they prefer heavier, more highly powered sprayers than are general in British Columbia. Growers who have to spray more than about 15 acres of trees have found that it is less economical to use a low-powered machine than a larger one; the larger machines do a better job at high speeeds.

\section{ASSESSMENT OF SPRAYERS}

Suggesting the arbitrary level of 100 microns in droplet diameter to differentiate between sprays and mists, Brown (12) mentions that the main interest in orchard spraying now centers around the attainment of droplets with mass median diameters between 50 and 100 microns, i.e., mists. He adds: "There is a crying need for methods of obtaining droplet spectra of spray and mist blowers". Experience at the Summerland laboratory supports Brown's views. Indeed, what is needed is not merely a method, but a rapid method.

Ever since the project on concentrate spraying was begun in British Columbia, efforts have been made to develop a simple yet reasonably accurate means of assessing the performance of concentrate sprayers. In order to screen new machines or devices, a two-dimensional trial was devised, largely

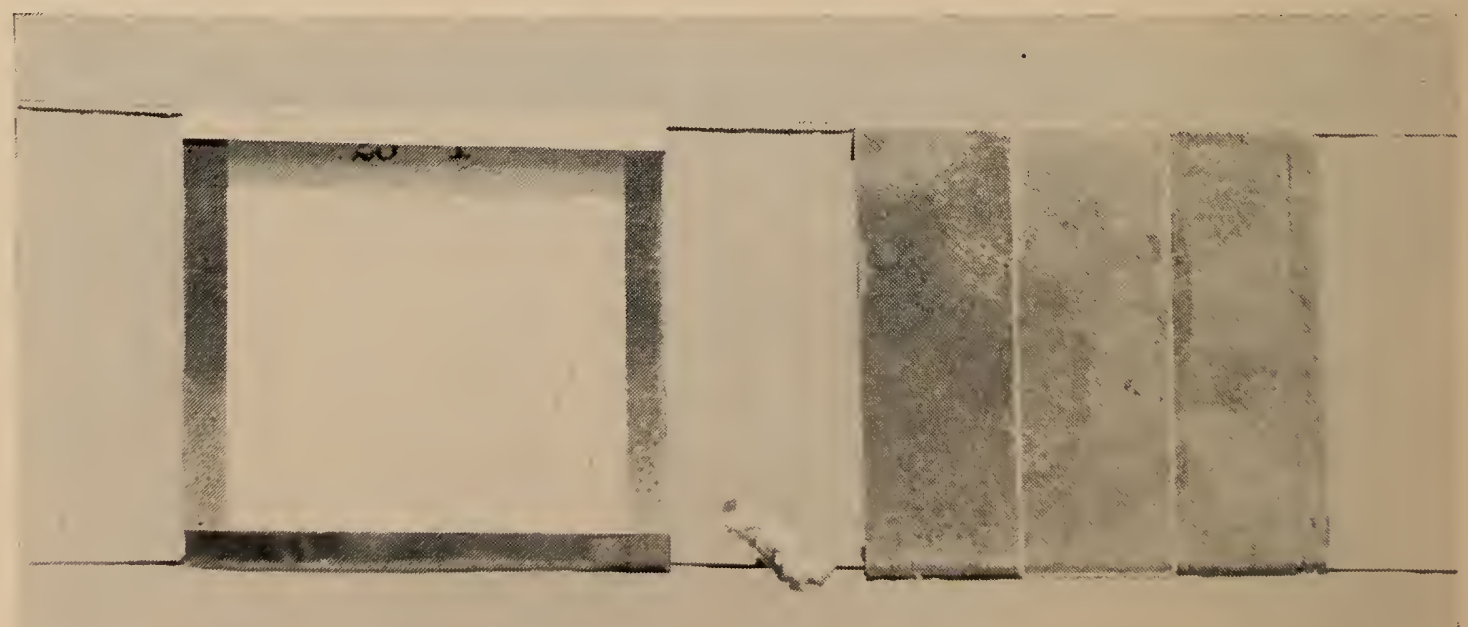

Figure 10-Targets used in sprayer assessment; left, treated card; right, treated microscope slide. 
by Messrs. D. B. Waddell and J. M. McArthur. It consists in operating sprayers past a frame 30 feet high and 30 feet wide, to the face of which are attached small targets. The targets are mounted in pairs; one of each pair is a glass microscope slide coated with a silicone preparation; the other, a white card treated with a benzene solution of a high melting point wax (Fig. 10). The slides and cards are so treated as to minimize the spreading of spray droplets and the penetration of the spray liquid. Equidistant from one another, at the five-foot level, are six pairs of such targets; six more pairs are directly above them at the 10-foot level, and so on at five-foot intervals to the 25 -foot level. Thus, on the face of the frame are 30 pairs of targets. Charged with a watersolution of the dye Rhodamine $\mathrm{B}$, at known concentration, the sprayers are driven past the spray frame at an angle of about 30 degrees, the first vertical row of targets being sprayed when the machine is 15 feet from the frame, and the last vertical row when the machine is five feet away (Fig. 11).

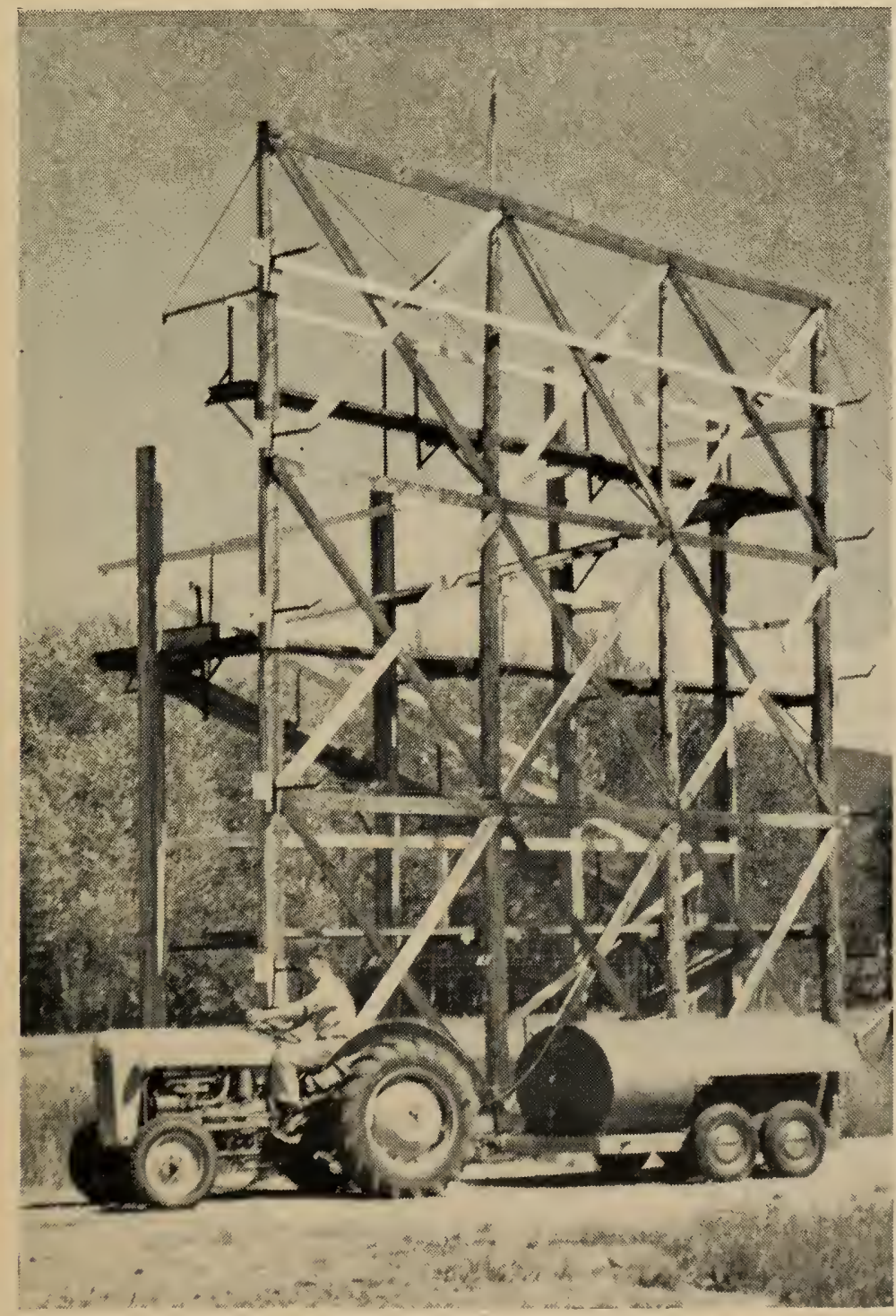

Figure 11-Spray-frame used in assessing orchard sprayers at the Entomology Laboratory, Summerland.

As soon as a trial run is completed the sprayed slides and cards are removed to numbered holders, and replaced by fresh slides and cards. A statistical analysis showed that reproducible results necessitate three runs for each experimental machine or device. Since each assessment involves comparison with a reference machine, six sets of 30 pairs of targets are required. 
After the spray droplets have dried, the microscope slides are washed in distilled water to remove the dye, the quantity of which is determined by means of a spectrophotometer. This procedure gives a reasonably accurate estimate of the mass of the spray per unit of area at various distances from the ground and from the sprayer. It does not, however, provide any information about the size or uniformity of the spray droplets. That is done by microscopic examination of the white target cards. Droplet diameter is approximated by dividing stain diameter by a factor that represents the spread of the droplet after impact.

Strips two inches by one inch in size are cut from the target cards, and so mounted on black photographic album paper as to represent their relative

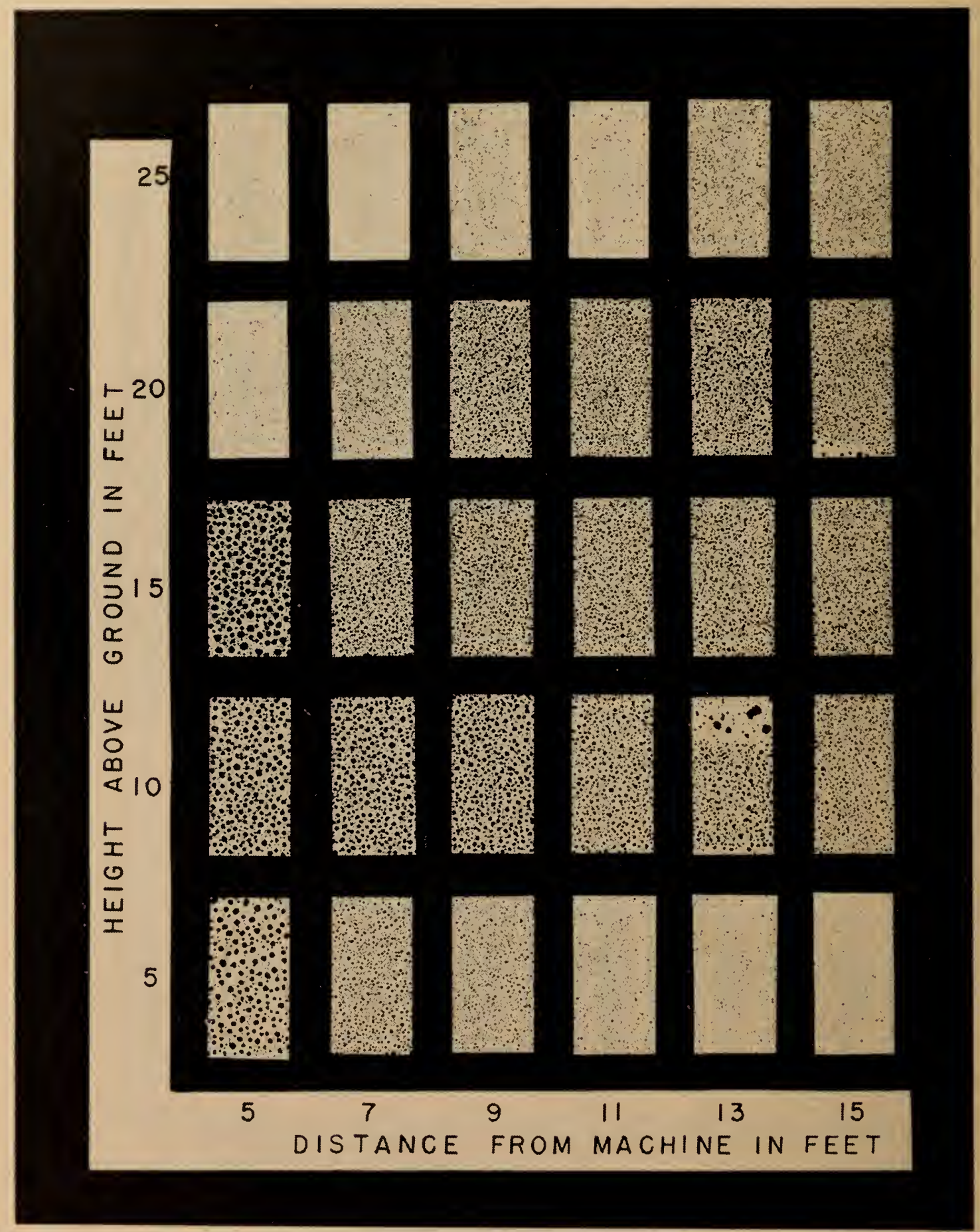

Figure 12-Mounted cards showing performance of an efficient concentrate sprayer. Note that all the targets received obvious spray coverage when the machine was 9 or 11 feet away from the spray frame. 
positions on the spray frame. Examination of the 30 mounted sprayed strips gives information on the spray pattern. Large stains on the lower cards, for example, indicate coalescence of droplets and overspraying. Little or no deposit on the uppermost cards indicates that the machine lacks capacity for spraying treetops (Fig. 13). A uniform, finely stippled deposit from the fivefoot level to the 25 -foot level, with the machine nine to 11 feet from the frame, is evidence of efficient operation (Fig. 12). Sometimes only the white cards are used in the assessment. But, when greater assurance is required, the glass slides and chemical analyses are brought into play. Then, as a final step, the evidence of performance from the mounted cards is compared with the data from the chemical analyses.

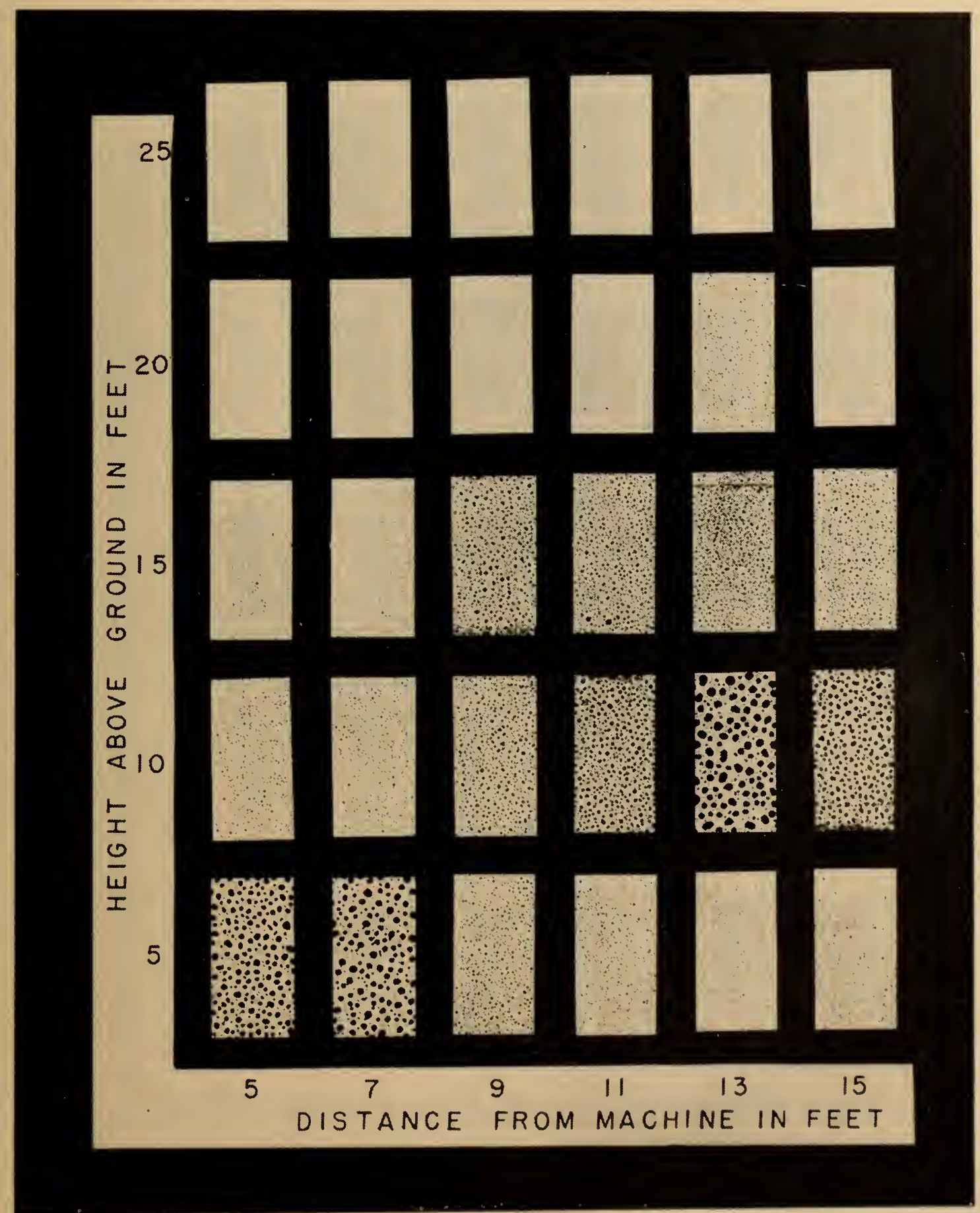

Figure 13-Mounted cards showing performance of an inefficient concentrate sprayer; heavy overspraying at low levels, insufficient coverage at high levels. 
In assessing concentrate spray equipment it is necessary to have a record of atmospheric air movement while each run is being made. An observer is stationed near the spray frame on a platform 10 feet high. While the sprayer is being driven past the spray frame he notes the wind direction and, by means of a velometer and an anemometer, the maximum wind velocity and the number of feet of air movement. These data are taken into account when it is desired to study the records of sprayer performance with particular care.

Use of the spray frame is restricted to preliminary screening trials. When a new machine, or a new component, gives results on the spray frame obviously inferior to those for the reference machine (a turbine-type, high-pressure, concentrate sprayer developed from the Okanagan experimental sprayer; air stream 6,700 to 7,000 c.f.m. at 110-115 m.p.h.), the new equipment is eliminated without further ado. If, however, it appears to be as efficient as, or more efficient than, the reference machine, it is subjected to orchard trials involving chemical analyses of samples from various levels in the trees and, if feasible, determination of effectiveness against whatever orchard insects or mites are available in adequate number.

The foregoing procedure for assessing concentrate orchard sprayers has proved most useful; but it is a laborious undertaking. The job of operating the sprayer, taking wind measurements, and changing targets requires the services of six people, and preparation of the targets and chemical and microscopic analyses necessitate many hours of careful laboratory work. Although the procedure does not provide highly accurate measurements of droplet size, it is questionable whether great precision is necessary for work of the kind. In assessing the performance of concentrate sprayers, the most obvious need, as mentioned earlier, is for greater speed rather than greater precision.

\section{RECOMMENDATIONS FOR SPRAYING}

It has been observed that advisers, or operators, who are unfamiliar with concentrate spraying, are prone to overestimate the amounts of spray chemicals necessary for it. Overlooking the great wastage from the drip, or "run-off", in high-volume spraying, they tend to assume that the quantities per acre for concentrate spraying are the same as for the old procedure. Chemical analyses, trials of effectiveness, and observations on phytotoxicity have shown that this is not the case. In the days of high-volume spraying in British Columbia, for example, 50 per cent DDT wettable powder was used at $1 \frac{1}{2}$ pounds per 100 gallons against the codling moth. Growers applied from 800 to 1600 gallons of spray liquid per acre, i.e., from 12 to 24 pounds of DDT. If an appropriate surfactant is added in the necessary amount, adequate deposits for all but the heaviest infestations are obtained when six pounds of DDT per acre are applied as spray concentrate. Again, in dormant spraying, a mixture of two gallons of heavy dormant oil and four gallons of lime-sulphur per 100 gallons of spray liquid was recommended in high-volume spraying against the San Jose scale, Aspidiotus perniciosus Comst., and about 500 gallons of spray liquid might be used per acre, i.e., 10 gallons of oil and 20 gallons of lime-sulphur. In concentrate spraying, on the other hand, similar results are obtained from six gallons of oil and 12 gallons of lime-sulphur.

By repeated experiment and observation the appropriate per-acre dosages of spray chemicals have been determined for British Columbia conditions. Since 1949, official recommendations for concentrate spraying have been made by the British Columbia and Canada Departments of Agriculture. The recommendations are prepared without reference to high-volume spraying; hence such terms as " $8 \mathrm{X}$ " and "semiconcentrate" are avoided. Undoubtedly the 
simplicity of these spray recommendations has been an important factor in the rapid adoption of concentrate spraying in the Province. The 1957 recommendations (2) which, in general, should be applicable elsewhere, are in part as follows:

"Speed of travel is most important in the successful operation of concentrate machines. For average size, mature trees, in full foliage applications, speed should not exceed one mile per hour (90 feet per minute). Disk openings should be checked frequently for any sign of wear. Use only materials listed for concentrate sprays. Shut off spray while making turn at end of row. Use smaller disks at lower end of nozzle-boom when excessive deposits are visible

\section{TABLE II}

Amounts of Spray Chemicals Recommended per Acre for Concentrate Spraying in British Columbia in 1957

\begin{tabular}{|c|c|}
\hline Spray Chemicals & $\begin{array}{l}\text { Pounds or } \\
\text { Imperial Gallons }\end{array}$ \\
\hline$\left\{\begin{array}{l}\text { Nicotine sulphate, } 40 \% \ldots \ldots \ldots \ldots \ldots \ldots \ldots \ldots \ldots \ldots \ldots \ldots \ldots \ldots \ldots \ldots \ldots \ldots \ldots \\
\text { Sodium carbonate (washing soda) } \ldots \ldots \ldots \ldots \ldots \ldots \ldots\end{array}\right.$ & $\begin{array}{l}\frac{1}{2} \mathrm{gal} . \\
2 \mathrm{lb} .\end{array}$ \\
\hline 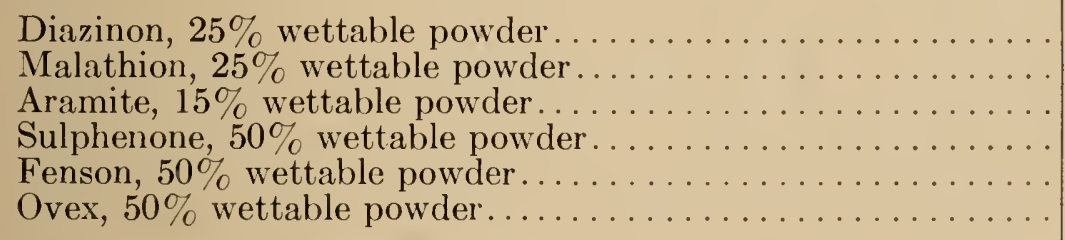 & $\begin{array}{l}12 \mathrm{lb} . \\
15 \mathrm{lb} . \\
12 \mathrm{lb} . \\
16 \mathrm{lb} . \\
4 \mathrm{lb} . \\
4 \mathrm{lb} \text {. }\end{array}$ \\
\hline$\left\{\begin{array}{l}\text { Dormant oil, } 200-220 \text { S.S.U. Vis.. } \ldots \ldots \ldots \ldots \ldots \ldots \ldots \ldots \ldots \ldots \ldots \ldots \ldots \ldots \ldots \ldots \ldots \\
\text { Dinitro-cresol wettable powder, } 40 \% \ldots \ldots \ldots \ldots \ldots \ldots \ldots \ldots\end{array}\right.$ & $\begin{array}{l}6 \text { gal. ( } 8 \text { gal. if } 75 \% \\
\text { emulsified oil is used) } \\
4 \mathrm{lb} .\end{array}$ \\
\hline 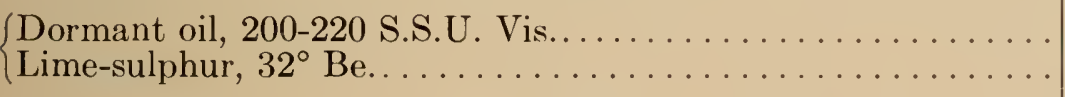 & $\begin{aligned} 6 & \text { gal. } \\
12 & \text { gal. }\end{aligned}$ \\
\hline 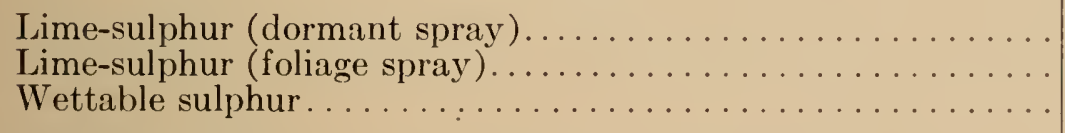 & $\begin{array}{rl}20 & \text { gal. } \\
8 & \text { gal. } \\
10 & \mathrm{lb} .\end{array}$ \\
\hline 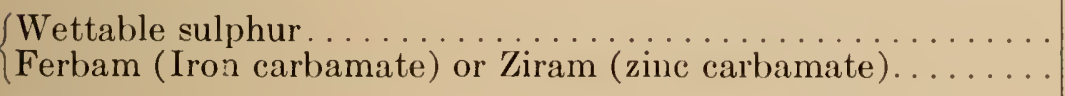 & $\begin{aligned} 15 \mathrm{lb} \\
5 \mathrm{lb}\end{aligned}$ \\
\hline 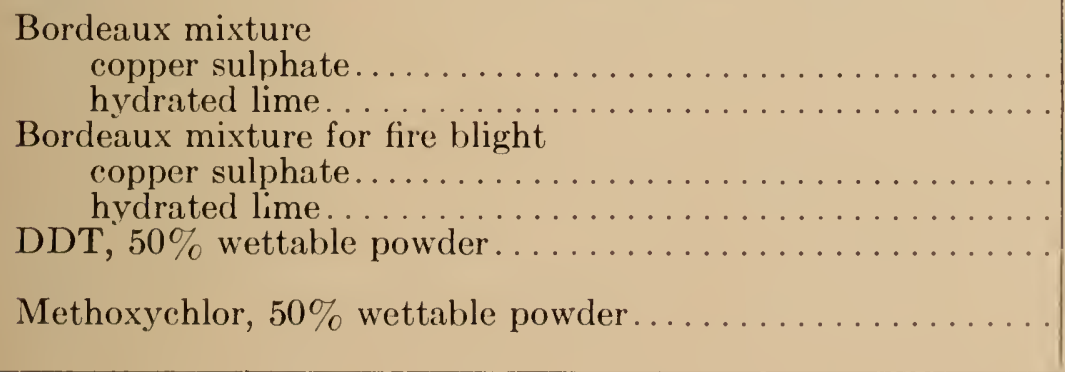 & $\begin{array}{l}25 \mathrm{lb} . \\
40 \mathrm{lb} . \\
3 \mathrm{lb} . \\
3 \mathrm{lb} . \\
12 \mathrm{lb} . \text { ( } 6 \mathrm{lb} \text {. if used with } \\
\quad \text { surfactant) } \\
12 \mathrm{lb} \text {. ( } 6 \mathrm{lb} \text {. if used with } \\
\quad \text { surfactant) }\end{array}$ \\
\hline
\end{tabular}

on lower portions of trees, (there should be no visible run-off). Amounts of chemicals for concentrate sprays... are recommended amounts per acre. Determine tank output on acreage basis; e.g., if tank covers $1 \frac{3}{4}$ acres use $1 \frac{3}{4}$ times the material shown in concentrate column above." 
Since "safe" chemicals are emphasized for concentrate spraying in British Columbia, the use of organic pesticides in liquid form is not recommended, and liquids formulated with organic solvents are generally avoided. Wettable powders are preferred; their abrasive qualities have been fairly well taken care of by the use of tungsten carbide nozzle discs and swirl plates; and the conspicuousness of their deposits, by surfactants. Restrictions as to type of formulation have helped to simplify the spray recommendations, a desirable thing when the recommendations otherwise tend to become more confusing year by year. Unusually abrasive formulations are avoided, as are heavily foaming preparations.

Table II shows that lime-sulphur has considerable prominence in the British Columbia spray recommendations. Since, just before the introduction of concentrate spraying, it had been largely superseded by less caustic, if less effective and less versatile, preparations, that is an interesting point. Limesulphur still ranks as one of the most useful and most economical spray chemicals and, in re-establishing its general use, concentrate spraying has conferred an unexpected dividend on the fruit growers.

\section{SUMMARY}

Experiments were begun in 1946 to reduce the labor and cost of spraying operations in the orchards of British Columbia. By 1956 virtually all the spraying was being done with light, concentrate sprayers modelled after the Okanagan experimental sprayer built in 1948. The change-over to concentrate spraying was accomplished without confusion, partly because most of the machines were of the same type, and partly because the recommendations for concentrate spraying were concise and easily interpreted.

Concentrate spraying is being rapidly adopted in the eastern and middiewestern United States and in Australia and New Zealand. Dutch, Danish, and British fruit growers appear to be turning increasingly to the new procedure.

Concentrate sprayers are defined as machines that cause no drip from the sprayed trees. They apply up to 75 imperial gallons of spray per acre of mature trees. The preferred dosage for British Columbia is 50 gallons.

The type of machine that, to date, has proved most practical for the majority of British Columbia fruit growers is a "one-side" sprayer weighing, with tank empty, from 1,500 to 1,800 pounds. It has a high-pressure pump, generates a linear-flow air stream, and is powered by a 25-horsepower gasoline engine. Operators of 50 acres or more generally prefer "two-side machines with double the capacity of the "one-side" models.

In British Columbia, concentrate spraying has proved as effective as commercial, high-volume spraying against insects, mites, and diseases of deciduous fruit trees, and has effected substantial savings in spray chemicals and labor; it has eliminated the wet clothing, drudgery, and discomforts of high-volume spraying.

The efficiency of concentrate sprayers is influenced by the velocity, the volume, and the type (turbulent or linear-flow) of the air stream, the design of the blower scroll and the air vent, the type of liquid manifold, the type of spray nozzle, the arrangement of the nozzles, the angle of emission of the spray liquid, the output of spray liquid, the pressure of the spray liquid (with swirl nozzles), and the rate of travel.

The homogeneity, volatility, viscosity, density, and surface-activity of spray concentrates have a bearing on atomization and on performance after impact.

The type of spray coverage obtained with concentrate sprayers is less efficient than would be expected from the amount of spray chemical that they 
deposit. The coverage can be made more nearly uniform and more efficient by the addition of certain non-ionic, water-dispersible, low-foaming, surfaceactive preparations (surfactants). The percentage of surfactant necessary is from 10 to 40 times as great as the percentage of wetter, or spreader, used in high-volume spraying.

In concentrate spraying, surfactants have improved the control of apple scab and the codling moth, but not of aphids nor of phytophagous mites.

With efficient, properly operated equipment, spray injury has not been more troublesome with concentrate spraying than with high-volume spraying. Lime-sulphur applied to dry trees has proved less prone to cause injury in concentrate spraying than in high-volume spraying.

Soil contamination by spray chemicals is distinctly less from concentrate spraying than from high-volume spraying.

A spray-tower technique has been developed for assessing the performance of concentrate sprayers. Its purpose is to screen out inferior equipment.

Amounts of spray chemicals recommended for concentrate spraying in British Columbia are considerably lower than for high-volume spraying.

Recommendations for concentrate spraying need be no more involved than those for high-volume spraying. The 1957 spraying recommendations for British Columbia are quoted to illustrate the point.

\section{ACKNOWLEDGMENTS}

Concentrate spraying could not have been quickly and soundly established in British Columbia without the aid of all members of the staff of the Summerland laboratory, the whole-hearted support of the Okanagan and Kootenay horticulturists of the British Columbia Department of Agriculture, and the confidence of the fruit growers. The entomologists, Messrs. R. S. Downing, C. V. G. Morgan, M. D. Proverbs, and D. B. Waddell all contributed useful observations and ideas. The chemists, Messrs. J. M. McArthur, J. R. W. Miles, and K. Williams, with their assistants, Messrs. F. E. Brinton and G. A. Wardle, carried out innumerable chemical analyses to determine spray deposits in the orchards, and played a leading part in the spray-tower assessment of new equipment.

Since $1955 \mathrm{Mr}$. A. D. McMechan, agricultural engineer at the laboratory, has been doing valuable work on the mechanical side of concentrate spraying. Messrs. G. D. Halvorson and G. F. Lewis, technicians, helped greatly by operating the various types of sprayers, experimental and otherwise, in the orchards, and by contributing ideas on modifications to simplify or improve operation of the equipment.

Mr. F. E. Owen, Defence Research Station, Suffield, Alberta, had much to do with the preliminary investigations, and built the prototype of Canadian concentrate machines, the Okanagan experimental sprayer. He deserves a particular word of appreciation because, in doing the job, he did not have the incentive of close association with the fruit industry.

Messrs. W. H. Robertson, Ben Hoy, and R. P. Murray, successive Provincial Horticulturists, arranged for the funds that were needed to build the Okanagan experimental sprayer, and have strongly supported the concentrate spraying investigations since they were begun. Among the Provincial district horticulturists, all of whom have been most helpful, special thanks must go to Messrs. E. C. Hunt, retired, and J. E. Swales, for the work they have done to establish concentrate spraying in the Kootenay Valley.

A final word of thanks goes to the three sprayer manufacturers who kindly contributed machines, and ideas, to further the investigations: Okanagan Turbo Sprayers Ltd., Penticton, British Columbia; Trump Ltd., Oliver, British Columbia; and Besler Engineering Corp., Emeryville, California. 


\section{REFERENCES}

1. Akesson, N. B. Blower sprayer equipment for pest control. Implement Record 47: 27-30. 1950.

2. Anonymous. Control of tree-fruit pests and diseases. British Columbia Dept. Agr. poster, p. 1. 1957.

3. Anonymous. 1956 spray recommendations. State Coll. Washington Ext. Bull. 419 (rev.). 35 pp. 1956.

4. Besemer, A. F. H. Faktoren die van Invloed zijn op het Ontstaan van "Spuitbeschadigingen". Achtste Jaarlijks Symposium over Phytopharmacie. Mededel. Landbouwhogeschool en Opzoekingsstations Staat Gent 21: 483-496. 1956.

5. Beskine, J. M. The use of the low volume mist blower. World Crops 4: 338-343. 1952.

6. Byass, M. A. Concentrate spraying: Will this nozzle solve the problems? The Grower 45: 1306-1307. 1956.

7. Brann, J. L., Jr. New methods for the application of insecticides to fruit trees. New York State Hort. Soc., Proc. 93rd Ann. Meeting: 100-106. 1948.

8. Brann, J. L., Jr., A. W. Avens, and R. W. Dean. The application of dormant oils as mists. J. Econ. Ent. 41: 180-185. 1948.

9. Brann, J.L., Jr. The use of mist concentrates on fruit trees. New York State Hort. Soc., Proc. 95th Ann. Meeting: 96-104. 1950.

10. Brann, J. L., Jr. Mist concentrates on fruit trees. New York State Hort. Soc., Proc. 96th Ann. Meeting: 100-107. 1951.

11. Brann, J. L., Jr. Apparatus for application of insecticides. Ann. Rev. Ent. 1: 240-260. 1956.

12. Brown, A. W. A. Some principles of the application of liquid insecticides. Pesticide Application Equip. Conf., Cornell Univ. Mimeo. 21 pp. 1955.

13. Burrell, A. B. Concentrate spraying in New York State during 1952. New York State Hort. Soc., Proc. 98th Ann. Meeting: 142-148. 1953.

14. Burrell, A. B. Concentrate method prevails in eastern New York. American Fruit Grower 73: 20, 44-47. 1953.

15. Courshee, R. J. How many gallons to the acre? The Grower 45: 338-341. 1956.

16. Cutright, C. R. Control of mites with concentrate sprays. Ohio State Hort. Soc., Proc. 82nd Ann. Meeting: 89-93. 1949.

17. Davies, C., and G. Smythe-Homewood. Investigations on machinery used in spraying. Part 1. Nozzles. J. South East Agr. Col. (Wye, England) 3: 39-62. 1934.

18. Edwards, C. J., and W. E. Ripper. Droplet size, rates of application, and the avoidance of spray drift. British Weed Control Con., pp. 348-367. 1953.

19. French, O. C. Spraying equipment for pest control. California Agr. Expt. Sta. (Berkeley) Bull. 666: 1-42. 1942. 
20. Foulds, R. M., G. L. Hey, and D. Hunnam. Low volume sprays for pest and disease control. The Grower 43: 941, 943, 945. 1955.

21. Garman, P. Efficiency of various orchard spray machines. J. Econ. Ent. 45: 345-346. 1952.

22. Garman, P. A study of spray machines in Connecticut orchards. Connecticut Agr. Expt. Sta. Bull. 567: 1-34. 1953.

23. Glass, E. H., and S. E. Lienk. Some problems in orchard spraying. New York State Hort. Soc., Proc. 98th Ann. Meeting: 135-141. 1953.

24. Goossen, H. Welche biologischen Forderungen werden an Pflanzenschutz geräte für den Feldbau gestellt? Z. Pflanzenkrank. Pflanzensch. 60: 561-568. 1953.

25. Goossen, H., and L. Eue. Distribution, resistance to rain, and translocation of spray and mist deposits in potato stands. Höfchen-Briefe (English Ed.) 8 (2): 65-84. 1955.

26. Griffiths, J., C. R. Stearns, and W. L. Thompson. Possibilities for the use of concentrated sprays on citrus in Florida. Proc. Florida State Hort. Soc. 63 (1950): 53-59. 1951.

27. Hamilton, J. M. Spray concentrates compared with standard concentrations for the control of apple scab and cherry leaf spot in 1950. New York State Hort. Soc., Proc. 96th Ann. Meeting: 158-165. 1951.

28. Harley, C. P. Are eastern apple growers taking the lead? Washington State Hort. Assoc., Proc. 50th Ann. Meeting: 12-15. 1954.

29. Hey, G. L. Concentrate spraying-These are the lessons of experience. The Grower 45: 763, 765, 767. 1956.

30. Hey, G. L. Programmes for controlling mildew. The Grower 45: 987, 989, 991. 1956.

31. Hoare, E. R. The world spraying problem. Farm Mechanization 4: 281-284. 1952.

32. Hunnam, D., R. M. Foulds, and E. Roney. Trials with Karathane for apple mildew. The Grower 45: 1375-1376. 1956.

33. Ingerson, H. G. The status of concentrate spraying of apples. North Central States Branch, American Assoc. Econ. Ent., Proc. 6th Ann. Meeting, pp. 30-31. (processed) 1951.

34. Kearns, H. G. H. Progress in automatic spraying. The Grower 43: 93-94. 1955.

35. Marshall, J. What will be future methods of spraying orchards and fields? Country Life in British Columbia, p. 18. Sept., 1946.

36. Marshall, J., and J. R. W. Miles. High-speed orchard sprayers and dusters. Washington State Hort. Assoc., Proc. 43rd Ann. Meeting: 108-114. 1947.

37. Marshall, J. Nozzle abrasion in orchard spray applicators. Sci. Agr. 31: 470-474. 1951.

38. Marshall, J., and J. R. W. Miles. Development of concentrate orchard sprayers in Canada. Proc. 7th Pacific Sci. Congr. 4: 196-206. 1949 [1953].

39. Marshall, J. Concentrate spraying for orchards. Nova Scotia Fruit Growers' Assoc., 91st Ann. Rept. 101-107. 1954.

40. Mitchell, A. E. The use of concentrate sprays in the apple orchard in 1948 and 1949. Ann. Rept. Secy. State Hort. Soc. Michigan 79 (1949): 25-29. 1950. 
41. Mitchell, A. E. Fruit finish, concentrate spraying and related problems. Virginia State Hort. Soc., Proc. 56th Ann. Meeting: 123-126. 1952.

42. Mitchell, A. E. Concentrate spraying. Michigan growers reduce spray costs, extend use to small fruits. American Fruit Grower 73 (2): 21-22, 23, 1953.

43. Moore, J. B., R. L. Webster, K. Groves, and H. Fallscheer. Investigations on codling moth and mite control. Washington State Hort. Assoc., Proc. 35th Ann. Meeting: 95-105. 1939.

44. Moore, M. H. An experiment in applying undiluted lime-sulphur to apple trees. East Malling Res. Sta. Ann. Rept. 1947, pp. 129-131. 1948.

45. Moore, M. H. Experiments in the use of lime-sulphur. The Grower 43: 243-245. 1955.

46. Nukiyama, S., and Y. Tanasawa. Physics of atomization of liquids in air [in Japanese]. Soc. Mechan. Engin. (Japan) Trans. 4: 86, 138; 5: 63, 68. 1940. Cited by Brown, A. W. A. in Insect control by chemicals, p. 355. New York, John Wiley and Sons. 1951.

47. Parker, K. G., and R. M. Pratt. The large air volume mist sprayer for use in the orchard. Connecticut Agr. Expt. Sta. Mist Blower Conf. Rept. Mimeo., pp. 16-18. 1948.

48. Parker, K. G. Further studies on mist spraying. New York State Hort. Soc. Proc. 95th Ann. Meeting: 105-108. 1950.

49. Parker, W. B. Vapo-Dust-a development in scientific pest control. J. Econ. Ent. 26: 718-720. 1933.

50. Pearch, L. C. Mist spraying at 50 gallons to the acre. The Grower 43: 879, 881. 1955.

51. Potts, S. F. Concentrated spray mixtures and their application by ground and aerial equipment as compared with standard spraying and dusting methods. United States Dept. Agr. Bur. Ent. Plant Quar. E-508. 25 pp. (processed) 1940.

52. Potts, S. F. Particle size of insecticides and its relation to application, distribution and deposit. J. Econ. Ent. 39: 716-720. 1946.

53. Potts, S. F., and R. B. Friend. Mist blowers for applying concentrated spray. In Connecticut State Entomologist, forty-fifth report, (Conn. Agr. Expt. Sta. Bull. 501) pp. 47-60. 1946.

54. Potts, S. F. Particle or droplet size of insecticides and its relation to application, distribution and deposit. Ohio State Hort. Soc., Proc. 80th Ann. Meeting: 193-205. 1947.

55. Pratt, R. M. The development of the new Cornell experimental sprayduster. New York State Hort. Soc., Proc. 92nd Ann. Meeting: 132-140. 1947.

56. Pratt, R. M. Status of the Cornell sprayer-duster. New York State Hort. Soc., Proc. 93rd Ann. Meeting: 87-93. 1948.

57. Ring, D. S. Report on results of concentrate spraying. New York State Hort. Soc., Proc. 96th Ann. Meeting: 97-98. 1951.

58. Sell, W. Staubausscheidung an einfachen Korpern und in Luftfiltern. Forschungsarb. Ver deut. Ing. V. I. D. Verlag 347: 1-12. 1931.

59. Sprague, R. Apple powdery mildew spray trials, 1955. Washington State Hort. Assoc., Proc. 51st Ann. Meeting: 52. 1955.

60. Srivastava, U.S., and P. D. Srivastava. Soap as spreader and insecticide. J. Econ. Ent. 49: 266-267. 1956.

¿: Swales, J. E., and K. Williams. Non-ionic surfactants in concentrate mixtures for the control of apple scab. Canadian J. Agr. Sci. 36: 36-40. 1956. 
62. Taylor, G. G. Application of orchard sprays. New Zealand Dept. Agr., Dept. Sci. Ind. Res. Bull. 22: 1-35. 1939.

63. Von Oppenfeld, H., D. Boynton, J. L. Brann, A. B. Burrell, and E. S. Shepardson. Cost and effectiveness of different insect and disease control practices in New York apple orchards. Cornell Univ. Agr. Expt. Sta. Bull. 886: 1-75. 1952.

64. Waddell, D. B., and J. M. McArthur. Effects of pruning on spray deposits from concentrate orchard sprayers. Canadian J. Agr. Sci. 34: 440-450. 1954.

65. Wittwer, M., and G. Müller. Versuche mit einem neuen Nebelverfahren zur Bekampfung der Kirschenfliege (Rhagoletis cerasi L.). Schweiz. Z. Obst.-u. Weinbau 62: 11-15. 1953.

66. Yeomans, A. H., and E. E. Rogers. Maximum deposit with elevation using a mist blower. United States Dept. Agr. Bur. Ent. Plant Quar. Special Rept. IN 2-22: 1-8. 1950.

67. Young, H. C. Symposium on the new methods for spraying fruit trees with special emphasis on concentrates. Disease control phase. Ohio State Hort. Soc., Proc. 82nd Ann. Meeting: 94-99. 1949.

68. Young, H. C. A progress report on the development of machines for application of concentrate sprays and the reduced costs resulting from their use. New York State Hort. Soc. Proc. 95th Ann. Meeting: 86-93. 1950.

69. Zimmer, S. J. The mechanics of spraying. World Crops 4 (10): 335-337. 1952. 


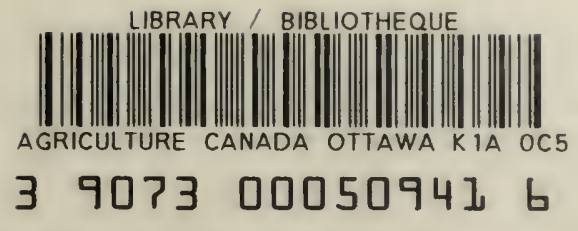


Price $\$ 1.00$

Cat. No A43-1020

Available from the Queen's Printer Ottawa, Canada 